\title{
Trabajo del hierro en la Ceuta islámica
}

\author{
Smithing work in Islamic Ceuta \\ Juan Aurelio Pérez Macías \\ José Manuel Pérez Rivera \\ Francisco Pereila Molina \\ Silvia Nogueras Vega
}

Recibido: $13 / 03 / 2017$

Revisado: 29/03/2017
Aceptado: $19 / 05 / 2017$

Publicado: 23/06/2017

\section{RESUMEN}

Se estudian en este trabajo los artefactos metalúrgicos exhumados en una excavación arqueológica preventiva llevada a cabo en el casco urbano de Ceuta, en conexión con una estructura de combustión que se ha interpretado como un hogar de forja. En paralelo a lo que sucede en otros asentamientos islámicos medievales de las costas de la Península Ibérica, se relaciona este tratamiento de minerales de hierro con la construcción naval. Se incide en la importancia de esta actividad desde al menos el siglo VI d.C. y su etapa de apogeo a partir de la segunda mitad del siglo XII con el establecimiento de la escuadra almohade en esta ciudad.

\section{Palabras Clave}

Norte de África; Ceuta; forja; medieval islámico; construcción naval.

\section{ABstRact}

In this article are studied the archeometallurgical remains exhumed in an archaeological excavation located in the centre of Ceuta (Spain, North Africa), in connection with a structure of combustion that has been interpreted like a forging workshop. As happens with other medieval Islamic settlements on the coasts of the Iberian Peninsula, the treatment of iron ores is related to shipbuilding industry. The importance of this activity is palpable since the 6th century, but even more in the second half of the twelfth century with the establishment of the almohade fleet in the city.

\section{KEY WORDS}

North Africa; Ceuta; forge; medieval islamic times; shipbuilding.

japerez@uhu.es

ceutadreams@gmail.com

lerzolita@hotmail.com 


\section{INTRODUCCIÓN}

Ceuta es una ciudad con una ubicación privilegiada (figura 1) y un largo recorrido histórico que ha generado una copiosa bibliografía (Villada Paredes, 2000). Los primeros signos de poblamiento prehistórico se han detectado en el abrigo de Benzú y en la cueva de Benzú (Ramos, Castañeda y Bernal, 2005). Por su posición adquiere relevancia durante la colonización fenicia, tal como ha puesto de manifiesto la excavación en la Plaza de la Catedral (Villada, Ramón y Suárez, 2010), y su importancia comercial se evidencia ya en época prerromana en las ánforas recogidas en la bahía de Benzú (Bernal Casasola, 2000), que reflejan un intenso tráfico comercial entre los siglos V y II a.C.

En época republicana debería pertenecer al reino mauritano. A partir de Augusto el reino mauritano pasó a formar parte de Roma, que puso al frente al rey Juba II, pero tras la revuelta mauritana contra Roma, se conquista definitivamente Mauritania y Claudio la divide en dos (42 d.C.), la Mauritania Caesarensis y la Mauritania Tingitana, a la que pertenecía Ceuta, que aparece denominada como Septem Fratres en C. Plinio (Naturalis Historia, $5,2,18)$. Con este nombre es también recogida por C. Ptolomeo (Geographica, 2, 4, 10) y como statio en el Itinerarium Antoninianum (I, 2,2). Era una ciudad estratégica en el paso del Estrecho de Gibraltar y alcanzó su mayor proyección económica a partir de época imperial gracias a las industrias de salazones. Fue promocionada a la categoría de municipio (Bernal, Pérez y Hoyo, 1999), y la ocupación romana está certificada además por abundantes materiales arqueológicos, restos de un acueducto (Arcos Quebrados), epígrafes, sarcófagos y variado material cerámico (Hernández Guerra,
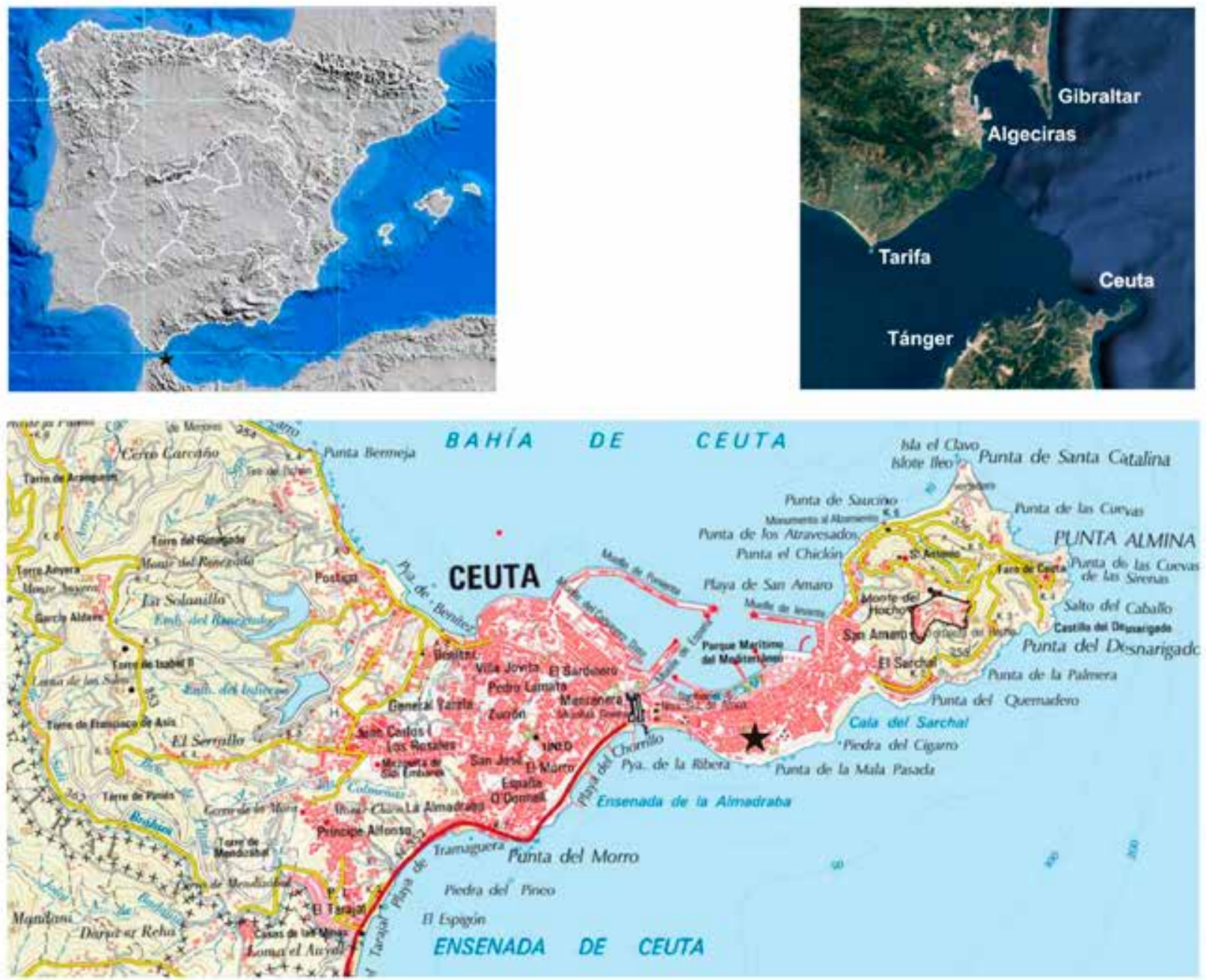

Figura 1. Ceuta y el Estrecho de Gibraltar. 
2005), entre los que destaca la evidencia epigráfica de un Iseum (Pérez y Bernal, 1995).

Diversos materiales avalan la importancia comercial de la ciudad en época bajo-imperial (Bernal Casasola, 1999), siendo significativas también las ánforas (Bernal Casasola 1996a y 1996b), que testifican el volumen de producción y comercialización de las industrias de salazones en estos siglos que se prolongan hasta la antigüedad tardía (Bernal y Pérez,1996). La circulación anfórica demuestra las estrechas relaciones comerciales de Ceuta con otras localidades del Norte de África y Oriente. En la antigüedad tardía se construyó además una basílica paleocristiana y a su alrededor se extendió un área cementerial, que confirman la consolidación del cristianismo (Fernández Sotelo, 1995 y 2005).

Sería ocupada y saqueada más tarde por los Vándalos, pero fue recuperada por las tropas bizantinas a comienzos del siglo VI (Vallejo Girvés, 2005). Dentro de los planes de recuperación de Justiniano, entre los años 533 y 534 el general Belisario conquista el reino vándalo del norte de África. Belisario envió a un legado, Juan, con el encargo de tomar Ceuta, abandonada por los vándalos, y la incorpora al imperio bizantino. Procopio, quien fue assesor de Belisario, nos comenta la conquista de Ceuta (De bello vandalico, IV, V, I), y nos dejó también la noticia de que Justiniano mando restaurar la muralla de Ceuta y construyó una iglesia dedicada a la Madre de Dios -Theotokos- (De Aedificis, VI, VII). La posición destacada que mantenía en la Mauritania Secunda (Vallejo Girvés, 2012), se acrecentó al ordenar Justiniano que estuviera bajo el mando de un tribuno militar y que fuera una estación para la flota de buques ligeros- dromones- (Cod. Iust. I, III, 27, 2, 2).

Esta ocupación bizantina debió preocupar a los visigodos, pues según S. Isidoro el rey Teudis organizó una expedición a Ceuta, para debilitar el poder bizantino y evitar la invasión de la península. La expedición debió realizarse entre los años 542 y 548 , pero fue un rotundo fracaso (Fita, 1916).

Se desconoce si siguió siendo una plaza bizantina o entró en la órbita visigoda, pero según las controvertidas noticias del Conde Julián fue también una plaza clave para la invasión musulmana de la Península Ibérica en el 710 (Vallvé Bermejo, 1989), y parece que en este momento el reino visigodo de Toledo ejercía una cierta influencia en la zona (Gozálbes Gravioto, 2011). Desde este año vuelve a ocupar una posición de privilegio en las comunicaciones entre la Península Ibérica y el Norte de África. Así ocurrió ya en la época emiral, cuando sirvió de refugio a las tropas sirias de Baly después de su derrota ante los beréberes. Destruida por los beréberes, es vuelta a conquistar por 'Abd al-Rahmān IIII al Nasir en 931 para hacer frente a la política de los fatimíes (Hita y Villada, 2003). Por su importancia geoestratégica para el paso del Estrecho, su puerto adquirió gran desarrollo comercial y se construyó una nueva muralla (Hita y Villada, 2004; Villada y Gurriarán, 2013).

Tras la época omeya formó parte de la taifa de Málaga, de la que se separó en 1061 al convertirse en reino independiente, hasta que fue conquistada por los almorávides. En época taifa llegó a acuñar moneda, a organizar una poderosa flota y a convertirse en un activo puerto comercial (Torremocha Silva, 2012).

Finalmente, los almorávides tomaron Ceuta con la ayuda de al-Mu'tamid, que había solicitado su auxilio para hacer frente a las tropas de Alfonso VI de León. En un principio Yusuf Ibn Tašufin instaló en Ceuta su corte, donde nació su sucesor Ali Ibn Yusuf en 1084. En esta época al-Idrīsī la describe como una ciudad de floreciente comercio gracias a la pesca del atún y a las industrias de coral (Hita y Villada, 2011). El paso del Estrecho se realizaba desde Algeciras hacia Ceuta o Tánger, y Ceuta destacó entre las ciudades del Estrecho junto con Tarifa, Algeciras y Tánger (Cherif, 2011). La ciudad experimentó grandes transformaciones (Martínez Enamorado, 1998; Ferhat, 1993) y se convirtió en el principal puerto del Mediterráneo occidental. Esta prosperidad continuó en época almohade, momento en el que se construirán más arrabales y otros edificios en Ceuta, entre ellos unas atarazanas (Terrase, 1962).

Desde 1232 Ceuta sufrió los ataques de Ibn Hud de Murcia y en 1242 los hafsíes tunecinos tomaron el control de la ciudad, hasta 1249 , en el que la dinastía local de los azafíes se hizo con el gobierno. Mantuvo su independencia de los meriníes a cambio de pagar tributo, y en 1278 colaboraron con ellos para el traslado de tropas para la invasión de la Península Ibérica. Los azafíes se mantuvieron en el poder hasta el 1310, en que pasaron a formar parte definitivamente del imperio meriní. En 1415 sería conquistada por los portugueses. 
A lo largo de esta historia Ceuta ha sido una ciudad volcada al mar (Pérez Rivera, 2005), y fue adquiriendo protagonismo, sobre todo como puerto para el paso del Estrecho de Gibraltar.

INTERVENCIÓN ARQUEOLÓGICA EN LA CALLE Eduardo Pérez Ortiz No 2 (Ceuta).

Los restos metalúrgicos que se estudian en este trabajo se localizaron en una intervención arqueológica preventiva llevada a cabo en una parcela formada por dos terrazas, situada entre las calles Eduardo Pérez Ortiz y Serrano Orive, en la zona alta de la Almina (figura 1). La realización de esta excavación estuvo motivada por un proyecto de construcción de viviendas, locales comerciales y garajes, ya que esta zona se encuentra en un área clasificada con Nivel 1 de Protección del Patrimonio Arqueológico por la Ordenanza Reguladora de la Disciplina Urbanística.

De manera previa se realizaron dos sondeos estratigráficos por medios mecánicos. El Sondeo 1 tenía unas dimensiones de $0,60 \mathrm{~m}$ de anchura por $6 \mathrm{~m}$ de longitud, y se alcanzó una potencia de $3,80 \mathrm{~m}$. La estratigrafía registrada sobre el substrato de esquistos alterados estaba formada por dos muros (M-101 y M-102), que conservaban un alzado de 1,80 m y tenían una anchura de 0,45 m, construidos con una fábrica mixta de mampostería y ladrillos con mortero de cal. Estos muros estaban relacionados con unidades sedimentarias de cronología bajomedieval. Sobre estos estratos medievales descansan niveles contemporáneos muy ricos en cerámica, vidrios y restos faunísticos, y un pozo de $0,70 \mathrm{~m}$ de profundidad. El Sondeo 2 tenía unas dimensiones de 6 por $2 \mathrm{~m}$ y fue estéril desde el punto de vista arqueológico.

Tras estas labores de sondeo se realizó una excavación. La ocupación arranca con un nivel con estructuras contemporáneas (tuberías y suelos). Bajo él se encontró un nivel homogéneo de coloración castaña con restos de fauna y cerámica medieval (UE 1004). Tras la eliminación de los restos contemporáneos, emergieron los muros de una estancia rectangular (M-101, M-102, M-104 y M-105). M-101 tenía una anchura de 0,50 m, una longitud de $3 \mathrm{~m}$ y una orientación suroeste-noreste. M-102 tenía la misma dirección y anchura que el anterior, y una longitud de 1,6 m. De M-104 solo se conservaban $0,80 \mathrm{~m}$ de longitud y apenas unos 0,30 $\mathrm{m}$ de anchura. M-105 era el más ancho, junto al que se identificó un sedimento compacto con inclusiones de cal, tejas y ladrillos (UE 1017). La fábrica de estos muros es de mampostería mixta, con mampuestos y una verdugada de ladrillos dispuestos a soga.

En el interior de la estancia formada por estos muros se localizó una estructura de combustión, de funcionalidad metalúrgica, que por la abundancia de escorias se interpretó como un horno de planta circular (figura 2 y 3). Según la estratigrafía se construyó en una zona que marcaba un
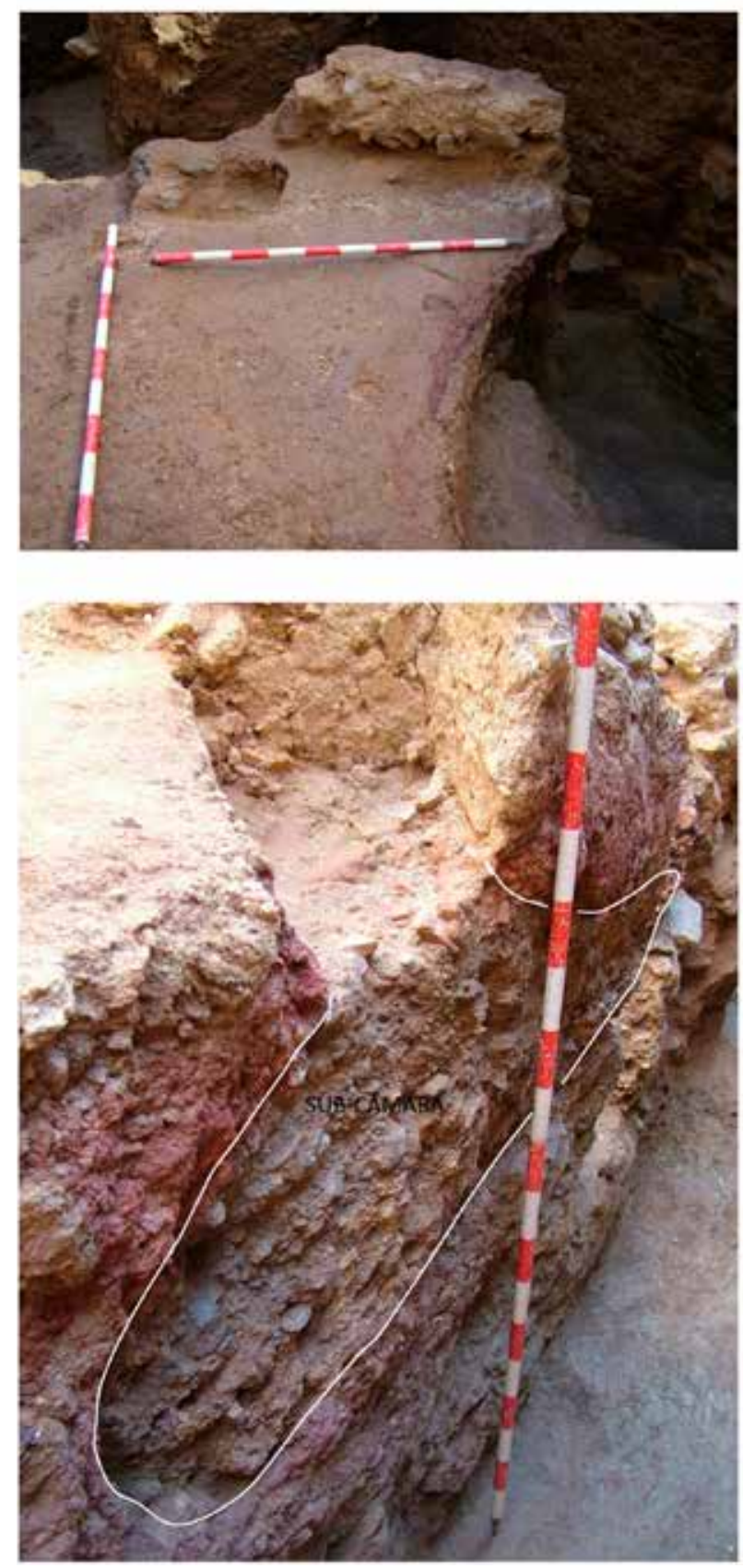

Figura 2. Pormenores del horno. 
pronunciado buzamiento en dirección este-oeste. Los muros M-105 y M-101 se levantaron sobre una fosa de cimentación de $0,40 \mathrm{~cm}$, rellena por tierras de textura arcillosa-arenosa de color grisáceo (UE 1044), de las que se recuperó un candil de piquera (figura 4). Sobre este nivel se depositó otro nivel de unos $10 \mathrm{~cm}$ de potencia y buzamiento al norte (UE 1043), de textura más gravosa, en el que hay que destacar una gran cantidad de fragmentos de escoria, que sirven de base al horno (HO 101).

La cámara del horno tiene unos 2,20 m de diámetro, y está abierta en el espacio entre los muros M-102 y M-105. Es de forma abovedada, de una altura de unos $0,5 \mathrm{~m}$, y en su parte superior presenta una abertura rectangular de $0,46 \mathrm{~m}$ por $0,38 \mathrm{~m}$, que haría las veces de chimenea. Sobre el suelo del horno había un nivel con abundantes escorias (UE 1045) y sobre ellas un estrato de colmatación formado por un sedimento de textura arenosa y color grisáceo, con inclusiones de
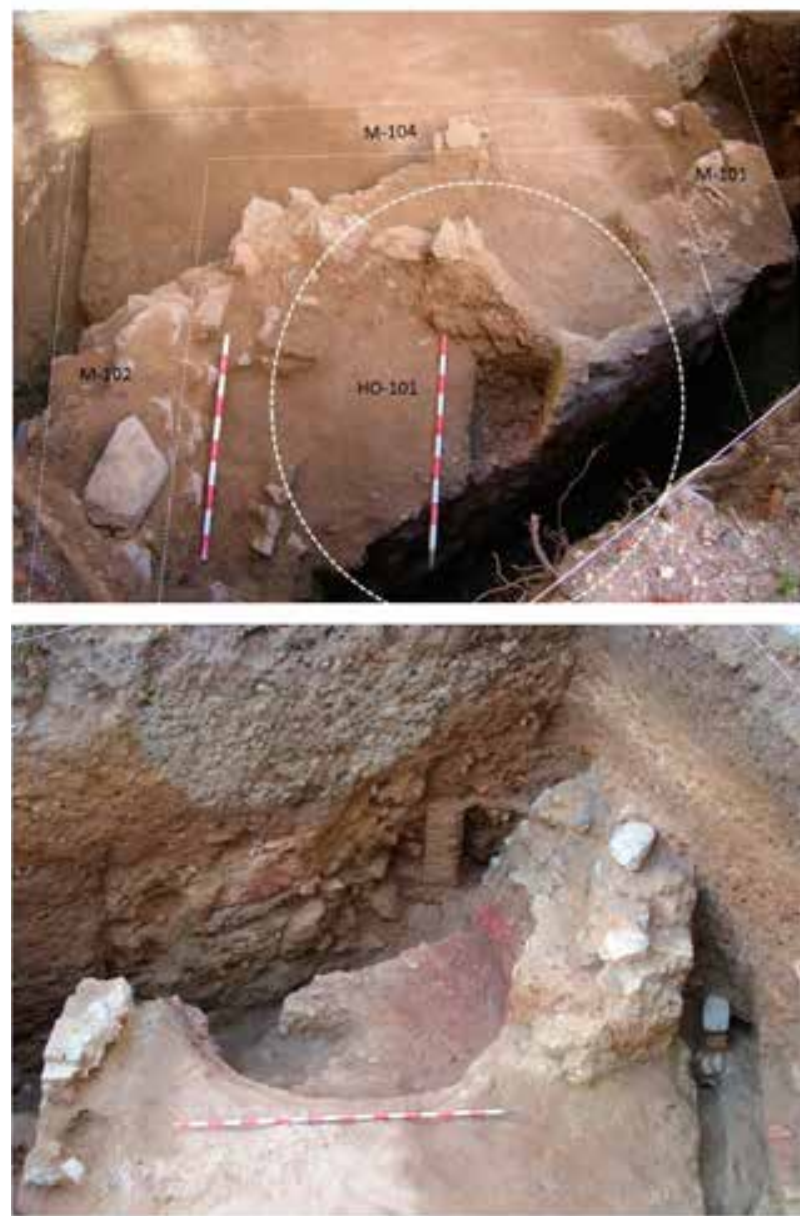

Figura 3. Pormenores del horno. carbones, material cerámico, entre los sobresale un fondo de una jarrita con decoración de cuerda seca parcial (figura 4), dos anafes y una torre de rueca en hueso, que deben ser materiales que amortizaron el uso de la cámara del horno. La estructura del horno fue construida con una gruesa capa de arcilla que ha adquirido un intenso color rojo como efecto de la rubefacción, pero no está escorificada, es decir, no ha servido de cámara de reducción.

Por encima del horno aparecía un sedimento de color verdoso e inclusiones de fragmentos de mortero blanquecino (UE 1040). Todo ello estaba relleno por una unidad de textura compacta, con carbones, restos de fauna, fragmentos de lebrillos y tejas (UE 1027).
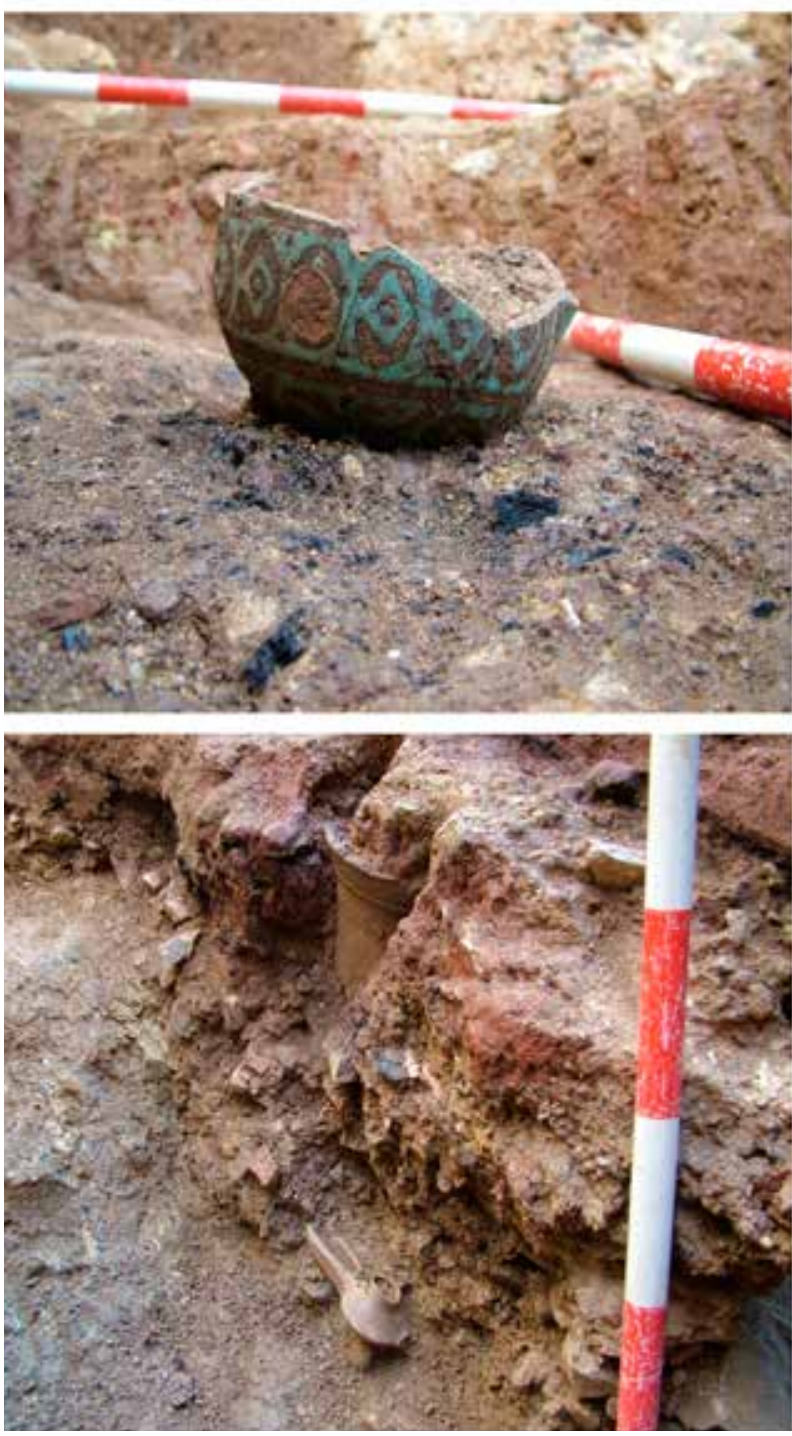

Figura 4. Materiales arqueológicos asociados al horno. 
En los alrededores del horno lo más significativo es un pequeño muro de ladrillos (M-106), que sirve de soporte a un suelo de ladrillos rectangulares (S102). El muro crea de este modo dos huecos rellenos por la UE 1033, de textura suelta, arenosa, con gran cantidad de fragmentos de ladrillos, piedras y material cerámico. Lo reducido del área excavada no permite relacionar la funcionalidad de estas estructuras con el horno.

Por otro lado, la estructura del horno se localiza entre dos calles (CA 101 y CA 102) y dos canalizaciones (C-101 y C-102). La primera conserva una longitud de 4,20 m y una anchura de 0,28, y continúa fuera de la zona de la intervención.

En la parte meridional del solar se exhumaron estructuras bajomedievales (M-103), con un nivel de suelo con fragmentos de ladrillos (S-101) y el sedimento de derrumbe de los muros de esta fase (UE 1025), muy ricos en materiales de construcción. Sobre ellos se encuentra la UE 1022, de textura arenosa y color castaño, cuyos materiales remiten a una cronología de fines del siglo XIV y principios del siglo XV.

Según las intervenciones llevadas a cabo en la zona de Almina, ésta comienza a ocuparse en un momento previo al período omeya (siglo $\mathrm{X}$ d.C.), como demuestran los materiales de las calles Fructuoso Miaja y Real (Hita y Villada, 2007, 116), y desde este sector la ciudad se extendería en primer lugar hacia el este-norte y posteriormente hacia el eje norte-sur. Toda esta zona de Almina se abandonaría a raíz de la conquista portuguesa de 1415 y no volvería a ser ocupada hasta finales del siglo XVII, momento que coincide con el cerco de Muely Ismail (1694-1727), pero no acabaría por ser urbanizada hasta el siglo XIX.

ANALISIS DE LOS MATERIALES METALÚRgICOS Y CARACTERIZACIÓN DEL HORNO.

De todos los fragmentos de escorias recogidas en la excavación se han seleccionado cuatro muestras procedentes de las unidades estratigráficas 1043 y 1045: 1043/1, 1043/2, 1045/1 y 1045/2. Su analítica se ha realizado en los Servicios Generales de Investigación y Desarrollo de la Universidad de Huelva mediante Microsonda de Electrones (EMPA), con un análisis general mediante ventanas de muestreo y análisis puntuales de las fases metalúrgicas y mineralúrgicas presentes en su espectro microscópico.
Por su aspecto se podían asociar a la metalurgia del hierro debido a la intensa oxidación exterior, propia de las escorias siderúrgicas. Algunas de ellas daban la sensación de corresponder más bien a hierros oxidados que se habían convertido en una masa remineralizada. Su análisis confirma en parte esta primera autopsia, pero nos detalla otros pormenores que ofrecen también gran interés.

$-1043 / 1$. Es un fragmento de escoria que conserva aún casi toda la superficie vitrificada. $\mathrm{Su}$ composición general es homogénea, con la característica composición fayalítica (silicato de hierro), pero con índice de hierro muy elevado que la relaciona con el tratamiento de minerales de hierro. La ausencia de valores detectables de cobre, plomo y plata confirma está clasificación. Su análisis general es el siguiente: 4,67\% Al, 20,43\% $\mathrm{Si}, 67,39 \% \mathrm{Fe}, 1,32 \% \mathrm{Mg}, 1,08 \% \mathrm{Mn}, 1,85 \% \mathrm{Ca}$, $1,01 \% \mathrm{~K}$, y $2,22 \% \mathrm{Ca}$ (figura 5).

Dentro de la muestra se han diferenciado varios espectros correspondientes a diversas fases metalúrgicas y mineralúrgicas. La más abundante es la de ferrosilicatos, con una composición de: $28,82 \% \mathrm{Si} \mathrm{O}_{2}, 64,53 \% \mathrm{Fe} \mathrm{O}, 0,09 \% \mathrm{Al}_{2} \mathrm{O}_{3}, 0,01 \% \mathrm{Bi}_{2}$ $\mathrm{O}_{3}, 0,007 \% \mathrm{Cu} \mathrm{O}, 3,08 \% \mathrm{Mg} \mathrm{O}, 0,03 \% \mathrm{~Pb}, 1,90 \%$ $\mathrm{Mn} \mathrm{O}, \mathrm{y} 1,06 \% \mathrm{Ca}$.

Otra de las fases más abundantes es la wüstita (óxido ferroso), con una composición muy cercana al hierro metálico (ferrita): 0,26\% $\mathrm{Si} \mathrm{O}_{2}, 97,12 \% \mathrm{Fe}$ $\mathrm{O}, 0,59 \% \mathrm{Al}_{2} \mathrm{O}_{3}, 0,02 \% \mathrm{Cu} \mathrm{O}, 0,15 \% \mathrm{Mg} \mathrm{O}, 0,06 \% \mathrm{~Pb}$ $\mathrm{O}, 0,028 \% \mathrm{~S} \mathrm{O}_{3}$, y $0,03 \% \mathrm{Ca} \mathrm{O}$. Los valores de cobre, plomo y sulfuro nos informan que en el mineral de partida se encontraban pequeñas formaciones de sulfuros de cobre-plomo.

Le siguen en importancia fases de silicatos de hierro con: $34,78 \% \mathrm{Si} \mathrm{O}_{2}, 0,35 \% \mathrm{Sb}_{2} \mathrm{O}_{5}, 20,83 \% \mathrm{Fe}$ $\mathrm{O}, 15,83 \% \mathrm{Al}_{2} \mathrm{O}_{3}, 0,20 \% \mathrm{Cu} \mathrm{O}, 0,16 \% \mathrm{Mg} \mathrm{O}, 0,003 \%$ $\mathrm{Pb} \mathrm{O}, 0,64 \% \mathrm{~S} \mathrm{O}_{3}, 0,40 \% \mathrm{Mn} \mathrm{O}$ y $10,75 \% \mathrm{Ca} \mathrm{O}$.

Junto a estas fases metalúrgicas hemos detectado también algunas drusas microscópicas de sulfuros de hierro-cobre (calcopirita) con la siguiente composición: $0,87 \% \mathrm{Si}, 37,78 \% \mathrm{Fe}, 0,09 \% \mathrm{As}$, $51,64 \% \mathrm{Cu}, 0,06 \% \mathrm{Ag}, 68,83 \% \mathrm{~S}$, y 0,39\% Ca. Este análisis nos ofrece la composición de los minerales primarios del yacimiento explotado, sulfuros de hierro-cobre con valores reseñables de arsénico, plomo y plata. La plata tiene una riqueza de unos 600 ppm (partes por millón) y debe proceder de la presencia de sulfuros de plomo en la mineralización. Aunque el mineral dominante es la calcopirita, 

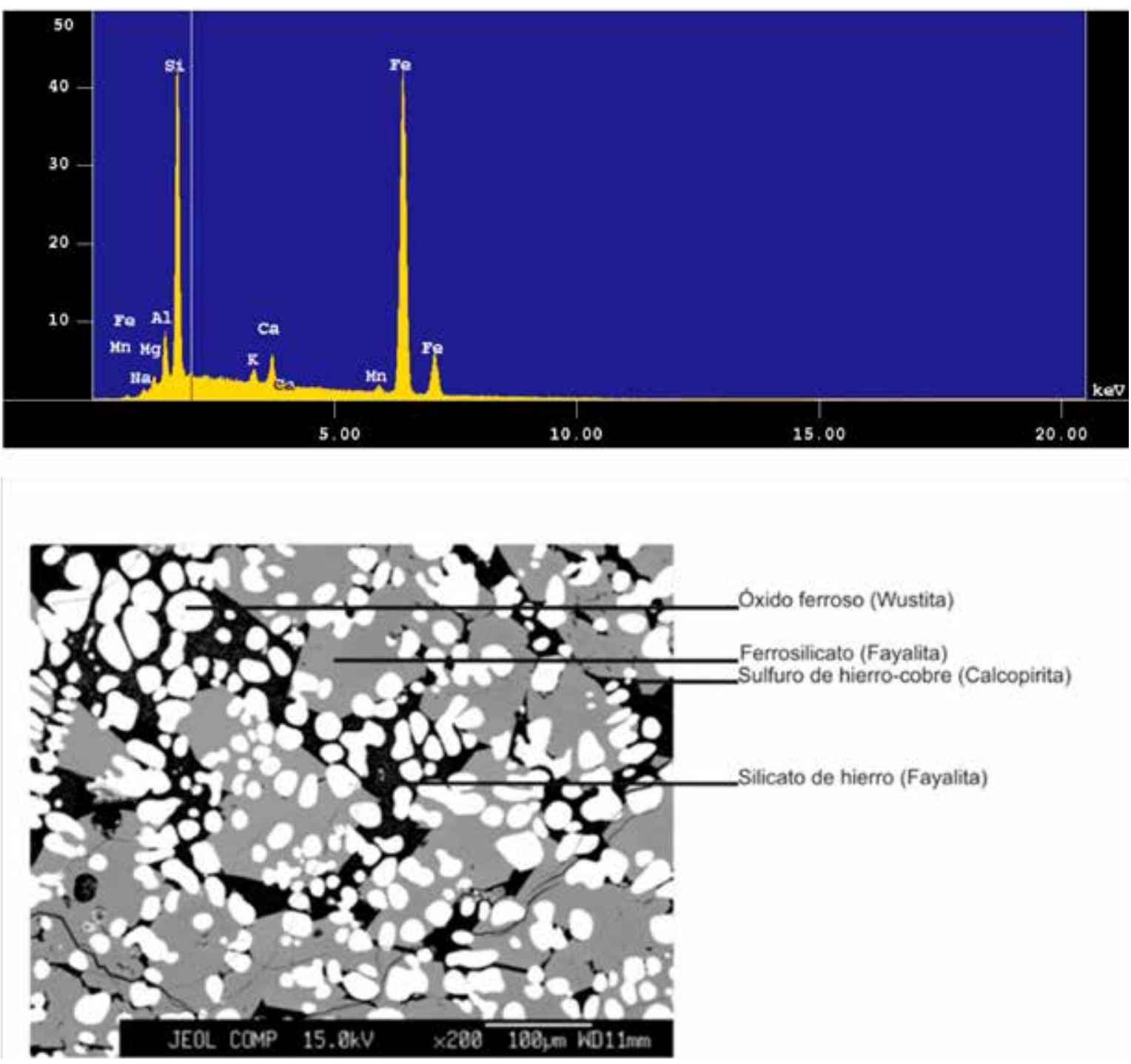

Figura 5. Espectro e imagen microscópica de la escoria 1043/1.

\begin{tabular}{|l|l|l|l|l|l|l|l|l|l|l|l|l|}
\hline $\mathrm{Al}_{2} \mathrm{O}_{3}$ & $\mathrm{Si} \mathrm{O}_{2}$ & $\mathrm{Sb}_{2} \mathrm{O}_{5}$ & $\mathrm{Fe} \mathrm{O}$ & $\mathrm{Pb} \mathrm{O}$ & $\mathrm{Bi}_{2} \mathrm{O}_{3}$ & $\mathrm{Cu} \mathrm{O}$ & $\mathrm{Mg} \mathrm{O}^{\prime}$ & $\mathrm{Zn} \mathrm{O}_{2}$ & $\mathrm{SO}_{3}$ & $\mathrm{Mn} \mathrm{O}$ & $\mathrm{Ca} \mathrm{O}$ & $\mathrm{K}$ \\
\hline 4,67 & 20,43 & & 67,29 & & & & 1,32 & & & 1,08 & 2,22 & 1,01 \\
\hline 0,09 & 28,82 & & 64,53 & 0,03 & 0,01 & 0,007 & 3,08 & & & 1,90 & 1,06 & \\
\hline & 0,26 & & 97,12 & 0,06 & & 0,02 & 0,15 & & 0,028 & & 0,03 & \\
\hline 15,83 & 34,78 & 0,35 & 20,83 & 0,003 & & 0,20 & 0,16 & & 0,64 & 0,40 & 10,75 & \\
\hline
\end{tabular}

Tabla 1. Fases metalúrgicas en 1043/1.

en la paragénesis del yacimiento se incluía una composición más compleja con plomo, arsénico y antimonio, que aparecen como elementos trazas en los análisis de las distintas fases metalúrgicas.
$-1043 / 2$. Esta escoria está muy oxidada y en algunos puntos se encuentra remineralizada. Su composición general tiene efectivamente menor cantidad de sílice y más hierro, aunque todavía 

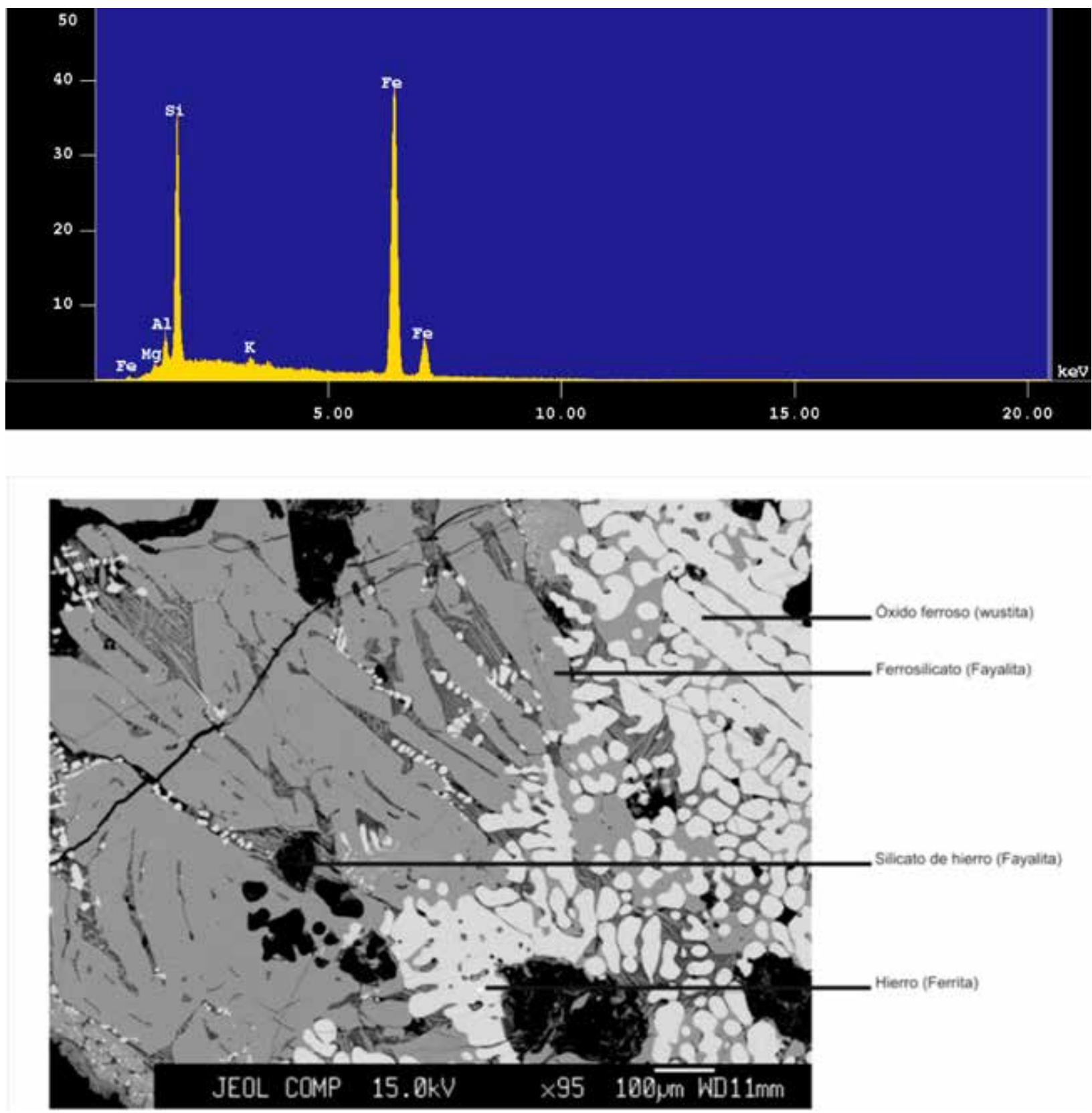

Figura 6. Espectro e imagen microscópica de la escoria 1043/2.

\begin{tabular}{|l|l|l|l|l|l|l|l|l|l|l|l|l|}
\hline $\mathrm{Al}_{2} \mathrm{O}_{3}$ & $\mathrm{Si} \mathrm{O}_{2}$ & $\mathrm{Sb}_{2} \mathrm{O}_{5}$ & $\mathrm{Fe} \mathrm{O}$ & $\mathrm{Pb} \mathrm{O}$ & $\mathrm{Bi}_{2} \mathrm{O}_{3}$ & $\mathrm{Cu} \mathrm{O}$ & $\mathrm{Mg} \mathrm{O}^{2}$ & $\mathrm{Zn} \mathrm{O}_{2}$ & $\mathrm{SO}_{3}$ & $\mathrm{Mn} \mathrm{O}$ & $\mathrm{Ca} \mathrm{O}$ & $\mathrm{K} \mathrm{O}$ \\
\hline 3,60 & 20,07 & & 73,78 & & & & 0,77 & & & 0,69 & 0,27 & 0,73 \\
\hline 0,08 & 27,07 & & 68,64 & 0,06 & & & 0,41 & & 0,01 & 0,58 & 0,17 & \\
\hline 0,97 & 0,31 & & 98,00 & 0,05 & 0,01 & 0,05 & 0,11 & & 0,007 & 0,22 & 0,01 & \\
\hline 21,34 & 33,51 & 0,35 & 29,98 & & 0,01 & 0,05 & 0,01 & 0,05 & 0,49 & 0,41 & 3,28 & \\
\hline
\end{tabular}

Tabla 2. Fases metalúrgicas en 1043/2. 
mantiene su naturaleza fayalítica: $3,60 \% \mathrm{Al}$, $20,07 \% \mathrm{Si}, 73,78 \% \mathrm{Fe}, 0,77 \% \mathrm{Mg}, 0,69 \% \mathrm{Mn}$, $0,27 \% \mathrm{Ca}, 0,63 \% \mathrm{~K}$, y $0,14 \% \mathrm{Na}$. El cobre y plomo no tienen valores detectables, y el alto contenido de hierro asegura su relación con la producción siderúrgica (figura 6).

Dentro de sus fases metalúrgicas destacan también los ferrosilicatos: $27.07 \% \mathrm{Si} \mathrm{O}_{2}, 68,64 \%$ $\mathrm{Fe} \mathrm{O}, 0,08 \% \mathrm{Al}_{2} \mathrm{O}_{3}, 0,002 \% \mathrm{Ag}_{2} \mathrm{O}, 0,41 \% \mathrm{Mg} \mathrm{O}$, $0,06 \% \mathrm{~Pb} \mathrm{O}, 0,03 \%$ Sn $\mathrm{O}_{2}, 0,01 \% \mathrm{~S} \mathrm{O}_{3}, 0,58 \% \mathrm{Mn}$ $\mathrm{O}$, y $0,17 \% \mathrm{Ca} \mathrm{O}$. Como en la muestra anterior, en esta fase queda parte de la composición de la ganga original del mineral, un sulfuro de plomo-plata.

A continuación le sigue una fase de wüstita, muy limpia de elementos de ganga y de una gran riqueza en hierro: $0,31 \% \mathrm{Si} \mathrm{O}_{2}, 98,00 \mathrm{Fe} \mathrm{O}, 0,97 \%$ $\mathrm{Al}_{2} \mathrm{O}_{3}, 0,01 \% \mathrm{Bi}_{2} \mathrm{O}_{3}, 0,05 \% \mathrm{Cu} \mathrm{O}, 0,11 \% \mathrm{Ag}_{2} \mathrm{O}$, $0,11 \% \mathrm{Mg} \mathrm{O}, 0,05 \% \mathrm{~Pb} \mathrm{O}, 0,007 \% \mathrm{~S} \mathrm{O}_{3}, 0,22 \% \mathrm{Mn}$ $\mathrm{O}$, y $0,01 \%$ Ca O.

En menor cantidad se encuentran las fases de silicatos de hierro: $33,51 \% \mathrm{Si} \mathrm{O}_{2}, 0,35 \% \mathrm{Sb}_{2} \mathrm{O}_{5}$, $29,98 \% \mathrm{Fe} \mathrm{O}, 21,34 \% \mathrm{Al}_{2} \mathrm{O}_{3}, 0,01 \% \mathrm{Bi}_{2} \mathrm{O}_{3}, 0,05 \%$ $\mathrm{Cu} \mathrm{O}, 0,01 \% \mathrm{Mg} \mathrm{O}, 0,05 \% \mathrm{Zn} \mathrm{O}_{2}, 0,49 \% \mathrm{SO}_{3}, 0,41 \%$ $\mathrm{Mn} \mathrm{O}$, y 3,28\% Ca O.

También aparecen pequeñas drusas de hierro metálico (ferrita) con algo de arsénico $(0,1 \% \mathrm{As})$, bismuto $(0,02 \% \mathrm{Bi})$, cobre $(0,08 \% \mathrm{Cu})$, y plata (0,04\% Ag).

$-1045 / 1$. Escoria que conserva su forma vítrea, aunque se encuentre oxidada. Su composición general destaca por el alto porcentaje de hierro, pero el sílice se mantiene en unos valores normales dentro de este tipo de escorias metalúrgicas: 8,09\% $\mathrm{Al}, 29,11 \% \mathrm{Si}, 55,35 \% \mathrm{Fe}, 1,00 \% \mathrm{Mg}, 0,90 \% \mathrm{Mn}$, $1,72 \% \mathrm{Ca}, 1,88 \% \mathrm{~K}, \mathrm{y} 1,91 \% \mathrm{Na}$ (figura 7 ).

Dominan las fases metalúrgicas de ferrosilicatos con: $29,01 \% \mathrm{Si} \mathrm{O}_{2}, 0,01 \% \mathrm{Sb}_{2} \mathrm{O}_{5}, 64,95 \% \mathrm{Fe} \mathrm{O}$, $0,53 \% \mathrm{Al}_{2} \mathrm{O}_{3}, 0,01 \% \mathrm{Cu} \mathrm{O}, 3,66 \% \mathrm{Mg} \mathrm{O}, 0,02 \% \mathrm{~Pb}$ $\mathrm{O}, 0,01 \% \mathrm{Zn} \mathrm{O}, 0,009 \% \mathrm{~S} \mathrm{O}_{3}, 1,43 \% \mathrm{Mn} \mathrm{O}$, y $0,34 \%$ $\mathrm{CaO}$.

Son también muy abundantes las fases de óxido ferroso, con: $0,37 \% \mathrm{Si} \mathrm{O}_{2}, 96,94 \% \mathrm{Fe} \mathrm{O}, 0,53 \%$ $\mathrm{Al}_{2} \mathrm{O}_{3}, 0,01 \% \mathrm{Cu} \mathrm{O}, 0,006 \% \mathrm{Mg} \mathrm{O}, 0,009 \% \mathrm{~Pb} \mathrm{O}$, $0,04 \% \mathrm{Sn} \mathrm{O}_{2}, 0,008 \% \mathrm{~S} \mathrm{O}_{3}, 0,42 \% \mathrm{Mn} \mathrm{O}$, y $0,04 \%$ $\mathrm{Ca} \mathrm{O}$. En menor cantidad se encuentran las fases de silicatos de hierro: $34,76 \% \mathrm{Si} \mathrm{O}_{2}, 0,36 \% \mathrm{Sb}_{2} \mathrm{O}_{5}$, $24,29 \% \mathrm{Fe} \mathrm{O}, 19,73 \% \mathrm{Al}_{2} \mathrm{O}_{3}, 0,32 \% \mathrm{Cu} \mathrm{O}, 0,006 \%$ $\mathrm{Mg} \mathrm{O}, 0,74 \% \mathrm{~S} \mathrm{O}_{3}, 0,32 \% \mathrm{Mn} \mathrm{O}$, y 5,39\% Ca O.

Aunque las fases de wüstita delaten que el origen de la muestra se encuentra en la reducción de un óxido o carbonato de hierro, los testimonios de antimonio, cobre, plomo y sulfuro coinciden con las analíticas anteriores.

$-1045 / 2$. Es una muestra mucho más oxidada y remineralizada, y la composición general demuestra que se debe a la menor proporción de sílice: 3,01\% $\mathrm{Al}, \quad 14,93 \% \mathrm{Si}, 76,65 \% \mathrm{Fe}, 1,51 \% \mathrm{Mg}, 0,61 \mathrm{Mn}$, $2,86 \% \mathrm{Ca}, 0,35 \% \mathrm{~K}$, y $0,05 \% \mathrm{Na}$ (figura 8).

Las fases metalúrgicas dominantes son las de ferrosilicatos, con: $27,50 \% \mathrm{Si} \mathrm{O}_{2}, 0,004 \% \mathrm{Sb}_{2} \mathrm{O}_{5}$,

\begin{tabular}{|l|l|l|l|l|l|l|l|l|l|l|l|l|}
\hline $\mathrm{Al}_{2} \mathrm{O}_{3}$ & $\mathrm{Si} \mathrm{O}_{2}$ & $\mathrm{Sb}_{2} \mathrm{O}_{5}$ & $\mathrm{Fe} \mathrm{O}$ & $\mathrm{Pb} \mathrm{O}$ & $\mathrm{Bi}_{2} \mathrm{O}_{3}$ & $\mathrm{Cu} \mathrm{O}$ & $\mathrm{Mg} \mathrm{O}^{\prime}$ & $\mathrm{Sn} \mathrm{O}_{2}$ & $\mathrm{~S} \mathrm{O}_{3}$ & $\mathrm{Mn} \mathrm{O}$ & $\mathrm{Ca} \mathrm{O}$ & $\mathrm{K} \mathrm{O}^{\prime}$ \\
\hline 8,09 & 29,01 & & 55,35 & & & & 1,00 & & & 0,90 & 1,72 & 1,91 \\
\hline 0,53 & 29,01 & 0,01 & 64,95 & & & 0,01 & 3,66 & 0,04 & 0,009 & 1,43 & 0,04 & \\
\hline 0,53 & 0,37 & & 96,94 & 0,009 & & 0,01 & 0,006 & & & & & \\
\hline 19,73 & 34,66 & 0,36 & 24,29 & & & 0,32 & 0,006 & & 0,74 & 0,32 & 5,39 & \\
\hline
\end{tabular}

Tabla 3. Fases metalúrgicas en 1045/1.

\begin{tabular}{|l|l|l|l|l|l|l|l|l|l|l|l|l|}
\hline $\mathrm{Al}_{2} \mathrm{O}_{3}$ & $\mathrm{Si} \mathrm{O}_{2}$ & $\mathrm{Sb}_{2} \mathrm{O}_{5}$ & $\mathrm{Fe} \mathrm{O}$ & $\mathrm{Pb} \mathrm{O}$ & $\mathrm{Bi}_{2} \mathrm{O}_{3}$ & $\mathrm{Cu} \mathrm{O}$ & $\mathrm{Mg} \mathrm{O}$ & $\mathrm{Sn} \mathrm{O}_{2}$ & $\mathrm{~S} \mathrm{O}_{3}$ & $\mathrm{Mn} \mathrm{O}$ & $\mathrm{Ca} \mathrm{O}$ & $\mathrm{K} \mathrm{O}^{\prime}$ \\
\hline 3,01 & 14,93 & & 76,65 & & & & 1,51 & & & 0,61 & 2,86 & 0,35 \\
\hline 0,13 & 27,50 & 0,004 & 67,08 & & 0,08 & & & & 0,003 & 1,63 & 0,20 & \\
\hline 0,03 & 0,03 & 0,01 & 84,74 & & & & & & & & 0,17 & \\
\hline
\end{tabular}

Tabla 4. Fases metalúrgicas en 1045/2. 

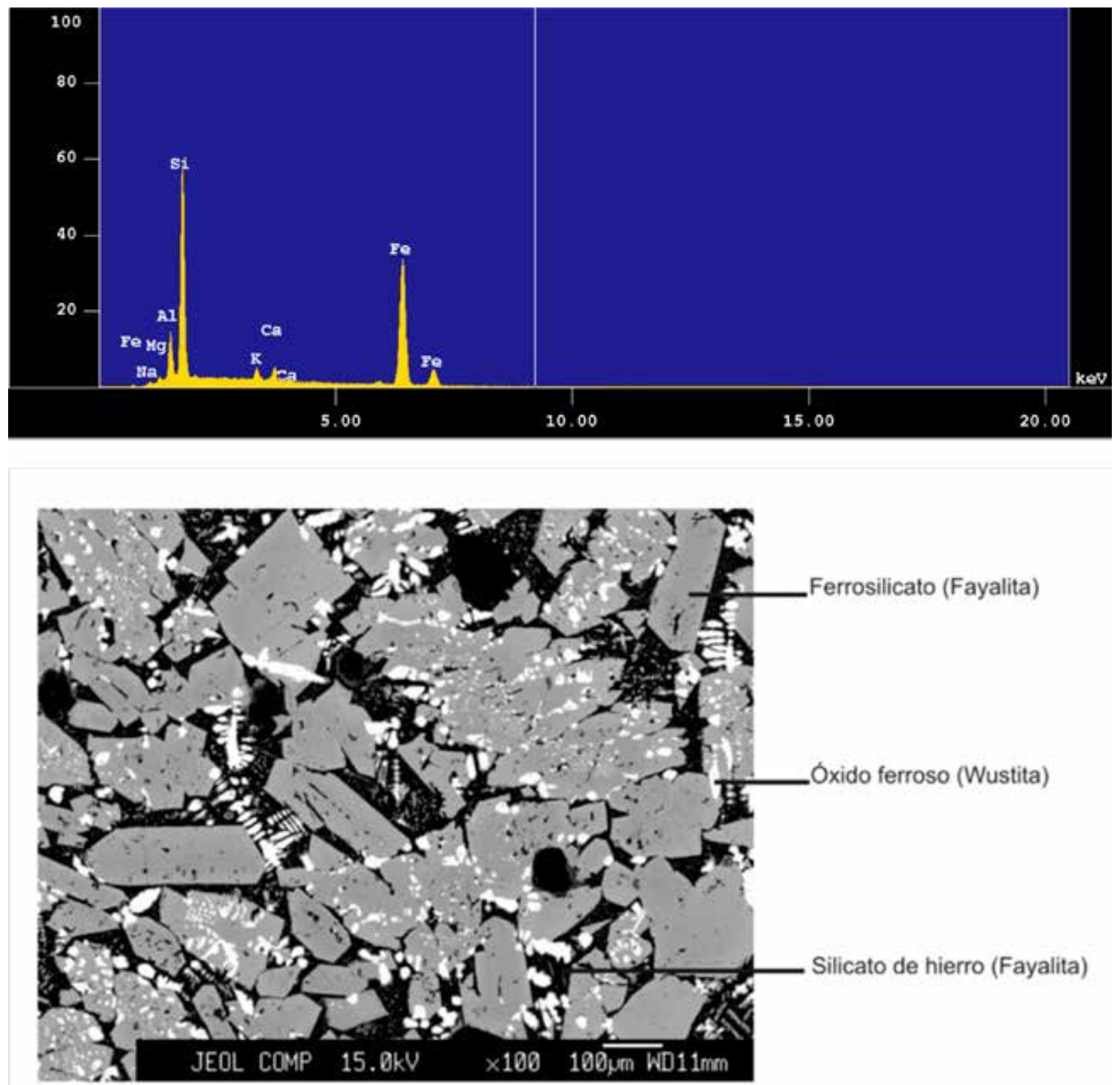

Figura 7. Espectro e imagen microscópica de la escoria 1045/1.

67,08\% Fe O, 0,13\% $\mathrm{Al}_{2} \mathrm{O}_{3}, 0,08 \% \mathrm{Bi}_{2} \mathrm{O}_{3}, 0,01 \%$ $\mathrm{Ag}_{2} \mathrm{O}, 0,003 \% \mathrm{~S} \mathrm{O}_{3}, 1,63 \% \mathrm{Mn} \mathrm{O}$ y $0,20 \% \mathrm{CaO}$.

Le siguen igualmente las fases de wüstita con: $0,03 \% \mathrm{Si} \mathrm{O}_{2}, 0,01 \% \mathrm{Sb}_{2} \mathrm{O}_{5}, 84,74 \% \mathrm{Fe} \mathrm{O}, 0,03 \%$ $\mathrm{Al}_{2} \mathrm{O}_{3}, 0,01 \% \mathrm{Bi}_{2} \mathrm{O}_{3}, 0,05 \% \mathrm{Cu} \mathrm{O}, 0,005 \% \mathrm{Ag}_{2} \mathrm{O}$, $0,58 \% \mathrm{Mg} \mathrm{O}, 0,01 \% \mathrm{~Pb} \mathrm{O}, 0,03 \% \mathrm{Sn} \mathrm{O}_{2}, 0,21 \% \mathrm{~S}$ $\mathrm{O}_{3}, 0,02 \% \mathrm{Mn} \mathrm{O}$, y $0,17 \% \mathrm{Ca} \mathrm{O}$. Existen algunas fases intermedias con mayores porcentajes de sílice: $3,21 \% \mathrm{Si} \mathrm{O}_{2}$ y $64,91 \% \mathrm{Fe} \mathrm{O}$.
Se encuentran asimismo algunas drusas de hierro metálico con impurezas de arsénico $(0,1 \%$ As), bismuto $(0,02 \% \mathrm{Bi})$, cobre $(1,11 \% \mathrm{Cu})$, plata $(0,04 \%$ $\mathrm{Ag})$, estaño $(0,03 \% \mathrm{Sn})$, manganeso $(0,07 \% \mathrm{Mn}), \mathrm{y}$ calcio $(0,03 \% \mathrm{Ca})$.

Desde el punto de vista analítico las muestras tienen una composición muy homogénea, no hay grandes diferencias entre ellas, y sus espectros microscópicos son muy monótonos, con predominio de fases de ferrosilicatos muy ricos 

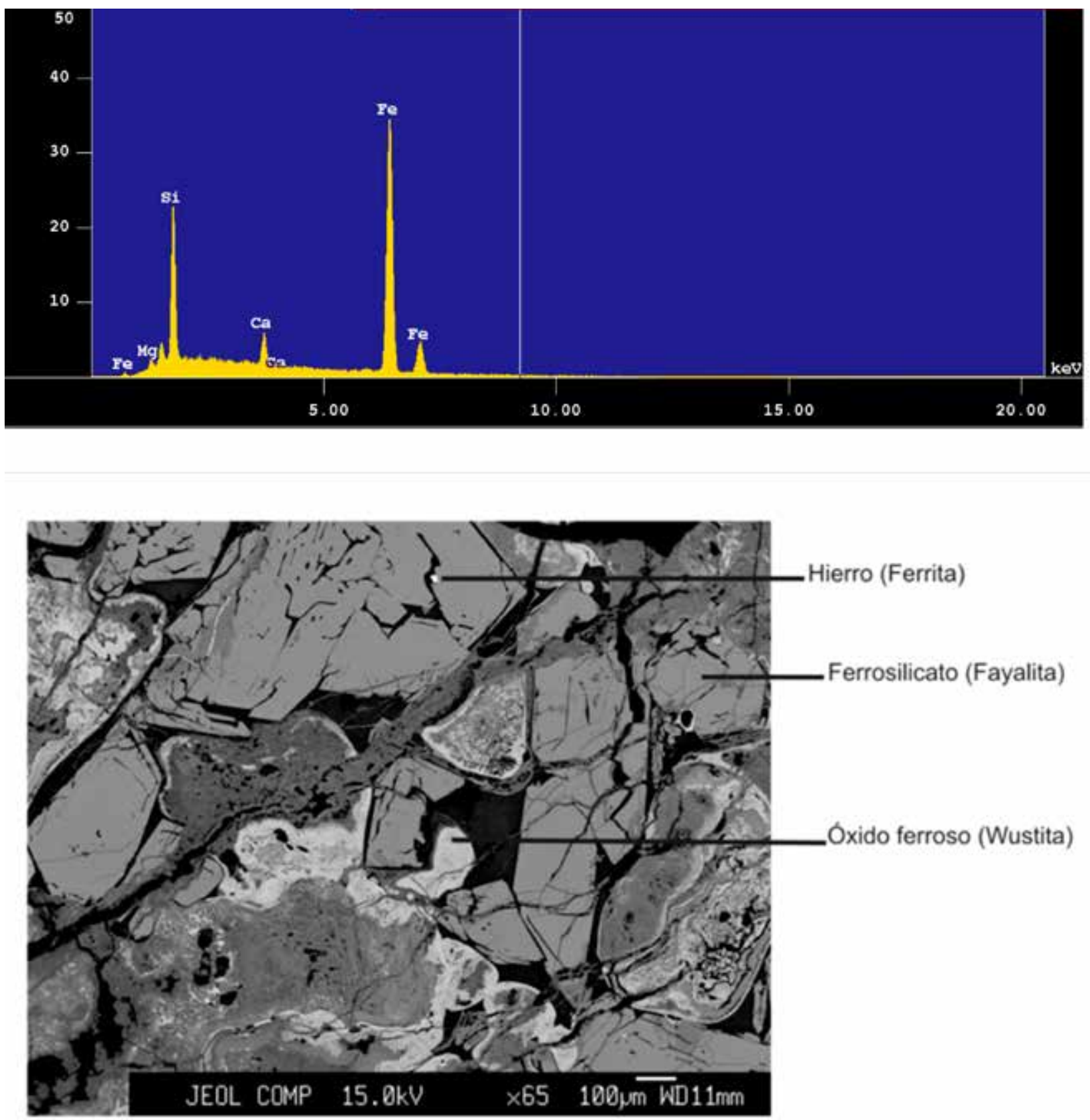

Figura 8. Espectro e imagen microscópica de la escoria 1045/2.

en hierro y fases de wüstita, y en menor medida fayalitas con valores normalizados de hierro y sílice. Estas analíticas las identifican sin ninguna duda con escorias siderúrgicas, formadas a lo largo de una operación de reducción de minerales. En este sentido, debe descartarse totalmente que el horno al que se encuentran asociadas corresponda a otra actividad productiva, hornos de cerámica, vidrio o cal, que también dejan escorias. Estos hornos también dejan escorias, pero no son de composición fayalítica, es decir silicatos de hierro. La fayalita se origina en el horno por la adición intencional de sílice y óxido de hierro como fundentes, para formar una fase metalúrgica diferenciada que atrapa aquellos elementos no deseables de la ganga.

Las formaciones de fases de wüstita las relaciona con la metalurgia del hierro (Bachmann, 1982), con el tratamiento de un óxido o carbonato de hierro, 
que en el proceso de reducción forma una mata de óxido ferroso como paso previo a la formación del hierro metálico (ferrita, hierro dulce). Las pequeñas drusas de hierro metálico que aparecen en las escorias confirman esta conclusión.

A pesar de su homogeneidad pueden señalarse además otras dos cuestiones. Una de ellas es que el valor del hierro es demasiado alto para ser consideradas escorias de sangrado de un horno de reducción de hierro. En estas escorias también aparece wüstita como fase singular y determinante de una operación siderúrgica, pero su abundancia en relación con las fases de silicatos de hierro las acerca a las escorias que se producen en los tratamientos de forja, en la limpieza de la esponja de hierro. A ello se debe también que las fases de ferrosilicatos se encuentran mejor representadas que las de los silicatos de hierro. El horno debe corresponder por tanto a un hogar de fragua para la forja del hierro (forja de purificación) y no a un bajo horno de reducción de hierro (Mangin, 2004). Sus dos metros de diámetro también se adaptan mejor también a este tipo de instalaciones de forja.

La segunda cuestión tiene que ver con la presencia de algunas partículas microscópicas de minerales remanentes, aquéllos que no llegaron a transformarse a lo largo del proceso de fundición. Hemos detectado que son básicamente sulfuros de cobre-hierro (calcopirita) con ciertas cantidades de arsénico, bismuto, antimonio, plomo, y plata, metales que también aparecen en las fases metalúrgicas de ferrosilicatos e incluso en las de hierro metálico. Su baja representación porcentual no permite considerar que eso se deba al tratamiento de un sulfuro para la producción de cobre (Salkield, 1970), pero si es evidente que se encontraban en los minerales tratados. Si la formación de wüstita se debe al tratamiento de un mineral de hierro (óxido y/o carbonato), esos minerales formarían parte de un mineralotecto en el que también existían relictos de sulfuros. Esto nos lleva a proponer que el yacimiento del que proceden estos minerales es una estructura filoniana de sulfuros de cobre-hierro, en cuya paragénesis se encuentran también minerales de plomo, arsénico, antimonio, y bismuto. La presencia de estos minerales primarios nos indica también que se está explotando la zona de oxidación, donde se encuentran los minerales de hierro, pero en las proximidades de donde comienzan a aparecer los sulfuros primarios. Finalmente, es muy significativo en todas las muestras el valor del calcio, por lo que deberíamos buscar la mineralización explotada en un yacimiento de contacto con calizas.

Las muestras minerales recogidas en la excavación son fragmentos de cuarzo con pintos de calcopirita, que coinciden por tanto con los sulfuros predominantes en las fases mineralúrgicas presentes en las escorias, donde además se encuentran minerales de plomo, antimonio y arsénico, y en menor medida bismuto, estaño y cinc.

Sobre las minas de Ceuta se conservan algunas noticias antiguas. El cronista de Ceuta A. Ramos Espinosa de los Monteros nos dejó algunas pinceladas de ellas en su obra: “... en la playa del Sarchal hay buenos pesqueros y en su rocha piedras para construcciones y manifestaciones de productos de minas..." (Ramos Espinosa de los Monteros, 1998, 206).

En ese mismo año Celestino García Fernández en su obra Geografía Médica de Ceuta nos comenta: “...En las montañas del Hacho son notables las calizas dolomíticas. En sus terrenos cretáceos se hallan la serpentina y la esteatita y en la vertiente sur de dicho monte, se distingue una roca azulada vulgarmente conocida como piedra del Sarchal, que viene a ser una piedra talcosa, cuyo color gris oscuro la hace asemejarse al mármol negro. Esta roca bastante dura, es fácil de labrar, untuosa al tacto y capaz de pulimento...En algunos sitios se encuentra el almagre, alguna pinta de cobre estratiforme, la ampelita grafica y ocres rojos y amarillentos" (García Fernández, 1987, 48-49).

En la obra Abyla Herculana de Francisco Sureda se amplían estas noticias:”...los estudios geológicos han descubierto en la zona de Ceuta lo siguientes minerales, de más o menos importancia comercial e interés industrial, hematites en los estratos cristalinos, calcopirita en el gneis del Monte Hacho y en las diversas perioditas....es indudable que todos estos minerales, debidamente explotados por la industria española, constituirían fuente de riqueza..." (Sureda Blanes, 1925).

Todos estos indicios mineros han sido investigados y evaluados por la moderna exploración geológica. Ceuta se encuentra dentro de la zona geológica del Rif septentrional (Chalouan et al., 2008). El Rif entra dentro de la zona más occidental del Cinturón Orogénico Magrebide y forma la rama sur del Arco de Gibraltar. El Arco de Gibraltar tiene tres dominios estructurales, las Zonas Internas o Dominio de Alborán, los Flyshs Magrebides, y las Zonas Externas. Las Zonas Internas son una serie 
de unidades geológicas desplazadas unos $500 \mathrm{~km}$ hacia el oeste, y en función de la recristalización metamórfica alpina se han reconocido dos complejos, uno inferior conocido como Sébtides, derivado del nombre árabe de Ceuta (Sebta), caracterizado por rocas de origen profundo de la corteza (micaquistos, granulitas, etc.) y peridotitas del manto superior, y otro superior conocido como Gomarides, que cabalga sobre el anterior y que está compuesto por rocas sedimentarias paleozoicas, algunos relictos mesozoicos-cenozoicos y rocas carbonatadas que se incluyen en la llamada Dorsal Caliza, de origen sedimentario.

Los distintos estudios geológicos de Ceuta, comenzados en 1846 por Coquand, han ido catologando la presencia de distintos yacimientos e indicios minerales/mineros, muchos de los cuales ya no existen en la actualidad. Los relacionados con nuestro estudio son:

- Yacimiento de antimonio Afriquita/San Pancracio (Coquand, 1846; Dëtienne, 1972; Arana et al., 1983). Situado junto al arroyo de las Bombas, pertenece al dominio antimonífero Fnideq-Beni Mezala (Sébtides), que está formado por doce minas concentradas a lo largo de una banda de unos 400 $\mathrm{m}$ de ancho y $4 \mathrm{Km}$ de largo de dirección NNE/ SSO (Chalouan, 2011). Las mineralizaciones son de tipo filoniano, en las que predomina el antimonio (Fkihech et al, 1990; Fkihech et al, 1991; Fkihech et al., 1992), pero también contiene minerales de hierro (pirita, arsenopirita, etc.), plomo (galena), cobre (calcopirita, bornita), cinc (esfalerita), plata (tetraedrita, pirargirita) y oro (Fkihech, 1997). Fue explotada por la sociedad Antimonio S.A. entre los años 1960 y 1979 (Arana y López, 1983).

- Yacimiento de antimonio Ayat (Morín, 1957). $\mathrm{Al}$ igual que Afriquita, pertenece también dominio antimonífero Fnideq-Beni Mezala (Sébtides). Se desconoce su ubicación concreta.

- Filón del Barranco del Príncipe (Agard et al., 1957), con calcopirita y galena en ganga de cuarzo (Gomárides).

-Filón del Tarajal (Marín y Beltrán de Lis, 1956). Plomo y cobre en rocas paleozoicas Gomárides.

- Filón de la Almadraba (Dupuy et al., 1917). Impregnaciones de hierro en una cantera de caliza en los alrededores de la playa de la Almadraba (Gomárides).

-Filón del Jardín de San Amaro ( Dupuy et al., 1917). Presencia de hematites en una cantera de caliza marmórea o mármol en los ortogneises del Hacho (Sébtides).

- Filón del barrio de San Amaro (Dupuy et al., 1917). Contiene calcopirita y arsenopirita en los ortogneises del Hacho (Sébtides).

- Filón de la playa del Sarchal (Coquand, 1846; Dupuy et al., 1917). Filones de calcopirita y arsenopirita en el contacto entre las peridotitas y el ortogneis del Hacho (Sébtides).

- Filón de las peridotitas del Sarchal (Marín y Beltrán de Lis, 1917). Inclusiones de magnetita en las peridotitas (Sébtides).

-Yacimiento de cobre del Hacho (J.M. Pérez Rivera y F. Pereila Molina, en estudio). Yacimiento de mineral de cobre en la costa sur del Hacho, asociado con filones de calcopirita y pirita.

Los estudios para la realización del mapa geológico de Ceuta escala 1:50.000 (Pineda et al., 2013), sólo señalan dos de estos yacimientos e indicios: Afriquita/San Pancracio y el barranco del Príncipe.

Para la producción de hierro se habrían minado los afloramientos de estas mineralizaciones, donde predominarían los óxidos y carbonatos de hierro, pero en el que también podían haber quedado atrapados algunos minerales primarios de cobre, como los que aparecen en las escorias en forma de elementos traza. Aunque no podamos demostrar con seguridad de qué mina proceden los minerales de hierro empleados en esta herrería, conviene señalar que los minerales de hierro no precisan de una minería complicada. Se encuentran en forma de carbonatos (siderita) y óxidos (gossan) en la parte más superficial de los yacimientos minerales, donde el contenido de hierro se ha concentrado por pérdida de otros elementos presentes en los sulfuros primarios. La presencia de contenidos residuales de minerales primarios de cobre, antimonio, etc., no es infrecuente en los yacimientos filonianos, donde suelen quedar retenidos restos de estos minerales en sectores no suficientemente alterados por la meteorización. Su minería no requeriría pues de una ingeniería avanzada, de contramina, como la que hay que llevar a cabo en la extracción de los minerales del enriquecimiento secundario, que necesita de medidas de planificación y control para el trabajo en profundidad y para la evacuación de las aguas que se acumulan en el interior de las labores. Teniendo en cuenta estas consideraciones, los minerales de esta herrería podían conseguirse con simples rafas superficiales que sigan el 
crestón de las estructuras filonianas, o bien con sencillas galerías (cañas) que fueran recorriendo longitudinalmente el filón a escasa profundidad, sin salir de la zona de oxidación, un tipo de minería que deja pocos testimonios arqueomineros susceptibles de ser datados de forma adecuada por una simple catalogación tipológica. Por ello, somos partidarios de considerar que pudieron ser los propios yacimientos mineros del entorno más próximo los que sirvieron para alimentar a esta herrería, y entre ellos se encuentran las minas del distrito antimonífero, como las cercanas de San Pancracio, o las estructuras filonianas del Barranco del Príncipe, Monte Hacho y Sarchal (figuras 1, 9 y 10).

En este tipo de herrerías medievales siempre que era posible se preferían minerales de hierro de altas cualidades siderúrgicas, como la magnetita, pero las técnicas siderúrgicas estaban tan desarrolladas en época islámica que se podían obtener magníficos hierros duros, perfectamente carburizados, a través de operaciones de reducción y de forja (recocido, templado y revenido), con las que era posible conseguir hierros ricos en austenita, cementita y martensita (Percy, 1964), que aumentan las propiedades del hierro, dotándolos de mayor dureza, resistencia y ductilidad. En al-Andalus se fabricaba el hierro $a l$-hind $\bar{l}$, el acero indio, que alcanzó justa fama entre las manufacturas andalusíes (Vallvé Bermejo, 1980).

Las dimensiones y características del horno de Ceuta no se adaptan a los hornos de reducción, es decir aquellos hornos en los que el mineral se convierte en metal bruto. Estos hornos son de cámaras de dimensiones mucho más reducidas, para poder alcanzar temperaturas superiores a los $1000^{\circ} \mathrm{C}$, la necesaria para la formación de la escoria (fayalita), y más aún en la metalurgia del hierro, ya que la formación del hierro metálico se produce a partir de los $1200^{\circ} \mathrm{C}$ (Pleiner, 2004). Además de sus pequeñas dimensiones, las paredes de los hornos de reducción conservan el interior escorificado, la parte que corresponde a la camisa de arcilla refractaria del interior del horno, donde se forman vidrios con la arcilla (silicatos de aluminio) o se pega a las paredes parte de la escoria que se va formando en el

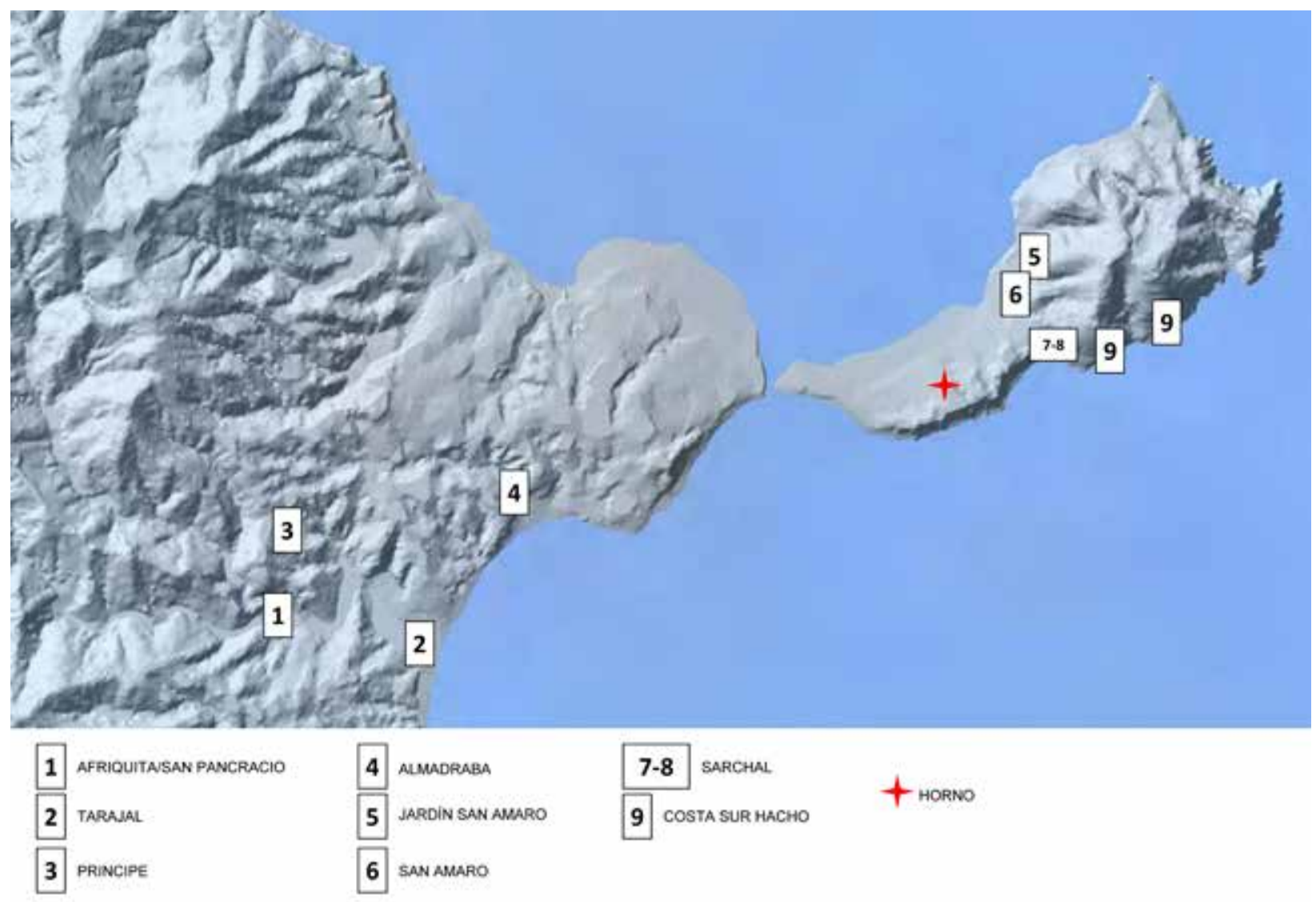

Figura 9. Entorno minero de la ciudad de Ceuta. 
interior (escoria de horno), pues no toda la escoria es posible eliminarla sacándola al exterior (escoria de sangrado).

Su forma y limpieza de cualquier tipo de escorificaciones conviene mejor a los hogares de forja, donde se manipula la esponja de hierro o el hierro dulce (ferrita), que conserva partes de escorias, para eliminársela, y para incorporarle carbono (carburación) y convertirlo en un hierro duro, al que se puede dar forma en caliente en el yunque, en el que se puede seccionar, ensanchar, estirar, curvar, torcer y soldar. Desgraciadamente, no se conservan muchos paralelos para este tipo de hogares en época islámica. Aunque los modelos de la antigüedad no tienen la misma tipología, como la conocida representación de una forja en un vaso griego de figuras negras (Tylecote, 1984, 45), sí son cámaras cerradas, abiertas en la parte delantera para introducir el hierro con las tenazas y con chimenea para la salida de humos. Más cercano en el tiempo es la representación de una forja en la Catacumba de Santa Domitila, que se encuentra en el Museo Cristiano de Letrán, en la que se distingue su hogar abovedado, abierto por delante y su yunque (Veyne, 1987, 272). La única diferencia con ellos es que el horno de Ceuta no es un elemento exento, está protegido por tres muros, para favorecer su resistencia, y es mayores dimensiones, un aspecto que avala su relación con una actividad industrial y no una producción doméstica para abastecimiento local.

\section{CONCLUSIONES}

La referencia más directa sobre esta minería y metalurgia del hierro en Ceuta la encontramos en la descripción de al-Ansari. Este autor menciona las minas de hierro y las relaciona con la construcción de barcos:"...las minas de hierro y rejalgar y otros productos de los que se beneficia la región para la construcción de barcos y para cuanto se refiere a la guerra santa. Todo esto se encuentra en el territorio próximo a la ciudad, que de ello se beneficia..."(Vallvé Bermejo, 1962, 441). El mismo al-Ansari sitúa las atarazanas en la zona de Madrib al-Sabika, en la zona de las Murallas del Mar (Vallvé Bermejo, 1962, 436), construidas en época almohade por el califa Jusuf I 'Ibn 'Abd al-Mu'min. Otras atarazanas de menos importancia se encontraban en la Bahía Sur y Bahía Norte.

Más noticias de estos arsenales ceutíes se encuentran en Mascarenhas (1995, 13-25): “...
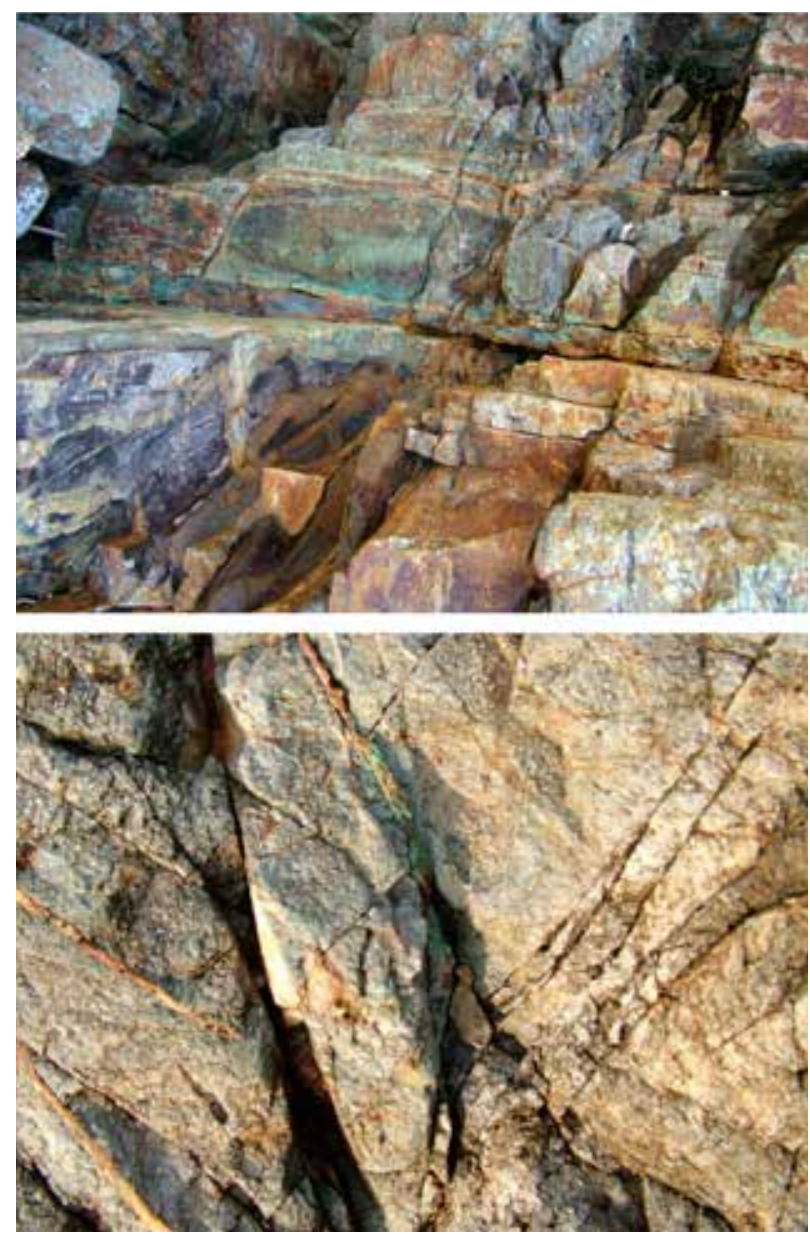

Figura 10. Formaciones filonianas de hierro-cobre en Monte Hacho.

destos escollos para la puerta del Campo ai dos playas grandes donde estuvieron las ataraçanas antiguas, como muestran los vestigios que oi se conservan.... Fue Ceuta de mayor grandeça en los siglos anteriores, i oi se manifiesta de sus ruinas, que como esta ciudad estuviese tan en el passo d' Hespaña, a que concurrian todas las naciones del mundo, por ser corta la trauiessa, passavan tambien á ella, i assi de mercaderes como de corsarios permanecen oi reliquias de ataraçanas, tanto en la mar de Levante como de Poniente... En una Crónica antigua manuscrita de los Reyes de Marruecos, q`traducida de lengua arábiga en la Castellana, se conserva entre los manuscriptos de mi estudio, hallo q'Joseph Aben - Jacob Rey de Marruecos edificó la casa de las ataraçanas (que este autor dice se conservaran en su tiempo) i q' hizo esta obra el año de los Arabes de 572 iqfue el mismo, en q`empezó a fundar la mesquita mayor de Sevilla...”. 
No es éste el único caso de producción de hierro en ciudades costeras relacionadas con la industria naval. El mejor conocido es el de la ciudad de Saltés. Sobre ella nos detalla al-Idrīsī:"...Ahí se trabaja el hierro, tarea que se rechaza a menudo porque es muy penosa, pero que es habitual en los puertos $\mathrm{y}$ en los lugares donde fondean grandes y pesados barcos de transporte..." (Roldán Castro, 2005). Igual relato sobre esta ciudad nos ofrece al-Himayarī:”... Hay allí un taller para la metalurgia del hierro, difícil trabajo al que no se dedican las gentes del interior y en el que se especializan los habitantes de los puertos frecuentados por los navíos...” (Roldán Castro, 2005), una noticia que es completada por al-Malīkī:"...En esta isla hay un centro metalúrgico donde se trabaja el hierro, que es una tarea para la que se considera incapacitada la mayoría de la gente. Ahí se fabrican las anclas con las que se detienen las naves..." (Roldan Castro, 2005). Esta actividad metalúrgica ha sido confirmada por las investigaciones arqueológicas desarrolladas en esta ciudad, en la que las escorias se encuentran dispersas por toda su superficie, y los talleres se situaban en el extrarradio urbano (Trauht, 2005)

La existencia de una flota en Ceuta se remonta a época bizantina. Procopio da noticia de que Justiniano coloca a Ceuta bajo la autoridad de un tribuno militar y establece en Ceuta una flota de barcos ligeros (dromones) para controlar el Estrecho y el Mediterráneo occidental. Con esa carpintería de ribera deben estar relacionadas las actividades metalúrgicas de Ceuta en los siglos VI y VII. En la parcela 21 de la Gran Vía se encontraron gran cantidad de escorias que se interpretaron "... como evidencia clara de actividades metalúrgicas realizadas por los contingentes militares aquí destacados, ... actividades de fragua/herrería para la reparación de los enseres o armamentos" (Hita y Villada, 2007, 106-107). Ceuta debería contar ya con un arsenal, y eso explicaría que el Conde Julián ofreciera a Tarif cuatro naves en el 710 para el paso del Estrecho. El paso definitivo lo daría Tariq en el 711 con un mayor contingente.

A raíz de la consolidación del estado omeya y sobre todo a partir de los ataques normandos a las costas de al-Andalus, se comprendió la necesidad de contar con una flota que impidiera las periódicas razias vikingas. Después de los ataques normandos 'Abd al-Raḥmān II construyó unas atarazanas en Sevilla. Se ha considerado que en este tiempo los movimientos de tropas en la región del Estrecho se realizarían mediante el alquiler de naves a particulares (Morales Belda, 1970, 84 ss.). Esto explicaría por qué algunos formularios notariales para el fletamiento de barcos fueron redactados por personajes de la zona, como al-Ŷazīrī y al Matītīi, ambos de Algeciras (Lirola Delgado, 1990).

La necesidad de contar con una escuadra también se hizo sentir en época de 'Abd al-Raḥmān III, cuando en el 914 tuvo que realizar campañas contra Málaga y Algeciras para interrumpir la ayuda que recibía Umar Ibn Hafsún del Norte de África. A partir de entonces se construyeron otras atarazanas en Algeciras y Málaga para el control de las aguas del Mediterráneo, y esto le permitió enviar una gran flota al Norte de África en el 931 (Lirola Delgado, 1991). La construcción naval estaba dirigida a proteger las costas de los ataques de normandos y fatimíes, y para ello se construyeron atarazanas en lugares estratégicos, en Alcácer do Sal, Almería, y Tortosa. La parte principal de la flota estaba fondeada en Almería, y es posible que continuaran en actividad las de Sevilla y Algeciras. Hay noticias también de que a comienzos del siglo XI había un arsenal en Denia (Torres Balbas, 1946). En esta época se reactivaría la flota de Ceuta debido a su política africana (Hita y Villada, 2003). En el siglo XII al-Idrīsī menciona las atarazanas de Tortosa, Alcácer do Sal, Denia, Silves y Alicante. En época almohade Abū Yàqūb Yūsuf mandó construir una gran atarazana en Sevilla, y se sabe que continuaba en actividad la de Denia.

La documentación de una importante producción de hierro en Algeciras, que se abastece de las minas de la zona Marbella, también pueden relacionarse con sus atarazanas (Jiménez-Camino, Suárez, Tomasseti, y Pérez, 2010). De igual modo, la existencia de importantes minas de hierro en el distrito de Denia, de las que se hicieron eco Estrabón, Pomponio Mela e Ibn Marrākušī (Navarro Oltra, 1998), hubo de ser una de las razones para la construcción de sus atarazanas.

En los siglos XI-XII al-Idrīsī menciona que uno de los sectores de mayor importancia en Ceuta era el de la construcción naval que se desarrollaba en el arsenal, dada la importancia que tenía para ella la defensa y el comercio (Hita y Villada, 2011). Este panorama industrial continuaría en época almorávide, cuando Ceuta se convierte en cabeza de puente para el paso de tropas a al-Andalus, especialmente desde la toma de Almería por los cristianos (Hita y Villada, 2009, 223). 
En época almohade Ceuta fue el centro de la flota almohade, desde donde la escuadra hacía salidas a donde era requerida. Así sucedió en 1179/80 para atajar los ataques a las costas por los portugueses según recoge Bayân al-Mugrib: “...En 577/1179-80 tuvieron lugar una serie de desmanes provocados por los cristianos, tanto por tierra como por mar, de forma que dio el emir al-mu'minin ('Abd alMu'min) a Ganim b. Mardānīsh el mando de la escuadra de Ceuta. Éste cruzó el mar en primer lugar para atacar la ciudad de Lisboa, se apoderó en ella de dos naves cristianas y se volvió a Ceuta..." (Huici de Miranda, 1953, 32).

La importancia de las atarazanas en los puertos del Estrecho también se hizo evidente en 1344, cuando la ciudad de Algeciras cayó en manos castellanas, lo que obligó a los meriníes a construir las atarazanas de Gibraltar (Piñatel et al., 2001).

En conclusión, la producción de hierro en Ceuta es un reflejo de la pujanza de su industria naval. Sobre la cronología de esta forja nos ofrece elementos de datación el nivel de colmatación de la cámara del hogar, que nos indica una fecha ante quem para su período de uso. Como ya se ha indicado, entre los materiales de esta unidad estratigráfica se encuentra un fondo de jarrita de vidriado verde en cuerda seca parcial. La decoración con cuerda seca es una de las técnicas más características de la cerámica andalusí. Se acepta su origen oriental, y su uso se extiende a partir del siglo XI por todo al-Andalus y al-Mughrib (Moreno Garrido, 1987). El momento de apogeo de esta técnica se produce en el siglo XI y primera mitad del siglo XII (Aguado Villalba, 1983), momento en el que se combina con otro tipo de decoraciones, como el estampillado o las incisiones (Gómez Martínez, 2002). De este modo, podemos situar el periodo de funcionamiento de esta forja entre mediados del siglo XI y primera mitad del siglo XII, y su probable abandono en época almohade, coincidiendo con la construcción de las nuevas atarazanas, donde se concentrarían probablemente las operaciones de reducción y forja del hierro que se necesitaba para armar los barcos de la escuadra andalusí. Tampoco debemos dejar de reseñar que es la primera vez que se documentan restos de una forja industrial en al-Andalus, y sus características pueden servir de modelo para otras instalaciones industriales de este tipo.
Bibliografía

Agard, J. y Diouri, M., (1957), Les gîtes mineraux de la zone nord, Rapport Service d'Études des Gîtes Mineraux, Rabat.

Aguado Villalba, J. (1983), La cerámica Hispanomusulmana de Toledo, Madrid.

Arana, R. y López, V. (1983), "Características mineralógicas del yacimiento de antimonita de San Pancracio (Ceuta)", Boletín de la Sociedad Española de Mineralogía, 7, 249-256.

Bachmann, H. G. (1982), The identification of the slags from archaeologial site, Institute of Archaeology, Occasional Publications, $\mathrm{n}^{\circ}$ 6, London.

Bernal Casasola, D.

(1991), "Lámparas bajo-imperiales de Ceuta", VIII Congreso Español de Estudios Clásicos, III, Madrid, 85-90

(1994), "Marcas sobre materiales de construcción de época romana en Ceuta, y la problemática de la necrópolis de las Puertas del Campo", Transfretana, 6, 61-80.

(1996a), "Le anfore tardorromane attestate a Ceuta (Septem Fratres) Mauritania Tingitana", L'Africa romana, 11, 1191-1233.

(1996b), "Las ánforas bajo imperiales y tardoantiguas del Museo Municipal de Ceuta”, Ánforas del Museo de Ceuta, Ceuta, 61-129.

(2000), "Hallazgos arqueológicos y estado de la cuestión sobre la presencia fenicio-púnica en Ceuta”, IV Congreso Internacional de Estudios Fenicios y púnicos, III, Cádiz, 11371151.

Bernal Casasola, D. y Pérez Rivera, J.M. (1996), "Nuevos datos sobre la presencia bizantina en Septem: avance preliminar de la excavación arqueológica en el Paseo de las Palmeras n⿳0 16-24”, Caetaria, 1, 19-129.

Bernal, D., Pérez, J.M., y Hoyo, J. (1999), “Epígrafe inédito hallado en Ceuta. Acerca del estatuto jurídico-administrativo de Septem Fratres”, $L a$ tomus, 58, 839-849.

Chalouan, A. (2011), "Le district á antimoine de Fridep-Beni Mezala (Rif septentrional)”, Les principales mines du Maroc (A. Mouttaqi, E.C. Rjimati, L. Maacha, A. Michard, A. Soulaimani y H. Ibouh, Eds.), Notes et Mémories Services Géologiques, 564, 351-355.

Chalouan, A., Michard, A. El Kadiri, K.H. y Negro, F. (2008), "The Rif Belt", Continental Evolution. The Geology of Marocco, structure stra- 
tigraphy and tectonics of the Africa-Mediterranean Triple Junction (A. Michard, O. Saddiqi, A. Choulan y A. Mouttaqi, Eds.), Lee Notes Earth Science, 116, 203-302.

Cherif, M. (2011), "La ciudad del Magrib al-Aqșà: el caso de Ceuta", Congreso Internacional Escenarios Urbanos de al-Andalus y el occidente musulmán, Málaga, 187-204.

Coquand, M. (1846), "Description géologique de la partie septentrionale de l'Empire du Maroc", Bulletin de la Société Géologique de Françe, 2 Série, 6, 1188-1249.

Détienne, J. L. (1972), Gisements antimoniferes de Beni Mezala. Etude geologique. Rapport Service d'Études des Gîtes Mineraux, nº 943, Rabat.

Ferhat, H. (1993), "Un monument almoravide: la grande-mosquée de Ceuta/Sabta (aproche textuelle)", Anaquel de Estudios Árabes, IV, 7785.

Dupuy De Lome, E. y Milans Del Bosch, J. (1917), "Estudios relativos a la geología de Marruecos: Zona de Ceuta”, Boletín del instituto Geológico de España, 18/2 $2^{\mathrm{a}}$ Serie, 27-63.

Fernández Sotelo, E.A. (1995), "La basílica tardorromana de Ceuta", II Congreso Internacional El Estrecho de Gibraltar, I, Madrid, 601-613. (2005), "Testimonios del Cristianismo en Septem", Ceuta de la Prehistoria al fin del Mundo Clásico, Instituto de Estudios Ceutíes, Ceuta, 171-184.

Fita, F. (1916), "Ceuta visigoda y bizantina durante el reinado de Teudis", Boletín de la Real Academia de la Historia, LXVIII, 622-628.

Fkihech, A., (1997), Mineralogía, geoquímica y metalogenia de los yacimientos de metales base y de antimonio del Rif interno (Norte de Tetuán, Marruecos). Tesis Doctoral. Universidad de Granada.

Fkihech, A., y Fenoll Hach-Ali, P., (1990), "Mineralizaciones de antimonio asociadas a calizas devónicas del Rif en las regiones de Ceuta y Tetuán (Marruecos). Datos preliminares”, Boletín de la Sociedad Española de Mineralogía, 13/1, 82-83.

(1992), "Composición mineralógica de los sulfuros y sulfusales de los depósitos hidrotermales del sector septentrional del Rif (N. de Marruecos)", Boletín de la Sociedad Española de Mineralogía, 15/1, 271-275.
García Fernández, C. (1987), Geografía médica de Ceuta, Ayuntamiento de Ceuta, Ceuta.

Gómez Martínez, S. (2002), A cerâmica em corda seca de Mértola, Mértola.

Hernández Guerra, L. (2005), "Epígrafes recuperados en la muralla romana de Ceuta", Florentia Iliberritana, 16, 353-363.

Hita Ruiz, J.M. y Villada Paredes, F. (2003), "Ceuta y la politica magrebi del califato omeya", $A l$ Andalus y el Mediterráneo en torno al año mil: la época de Almanzor (A. Torremocha y V. Martínez, Eds.), Algeciras, 141-156.

(2009), "Medina Sabta", Historia de Ceuta. De los orígenes al año 2000, I, Ceuta, 204-315. (2011), "La Ceuta que vió nacer a al-Idrisi”, $E l$ mundo del geógrafo al-Idrisi (F. Herrera Calvero, Coord.), Ceuta, 161-168.

(2007), Un decenio de arqueología en Ceuta 1996-2006, Ceuta.

(2004), "En torno a las murallas de Ceuta. Reflexiones sobre el amurallamiento de Septem Frates y la cerca omeya de Sabta”, Actas de las I Jornadas de Estudio de las Fortificaciones, Ceuta, 17-52.

Huici de Miranda, A. (1953), Crónicas árabes de la Reconquista, I, Tetúan.

Jiménez-Camino, R., Suárez, J., Tomasseti, J.M., y Pérez, J.A. (2010), "Herrerías en la Algeciras Omeya", Estudios de Minería Medieval en Andalucía (J.A. Pérez Macías y J.L. Carriazo Rubio, Eds.), Huelva, 63-98.

Lirola Delgado, J. (1990), "Modalidades del contrato de fletamiento de embarcaciones en al-Andalus", Miscelánea de estudios árabes y hebraicos, 38/1, 87-100.

(1991), El poder naval de al-Andalus en época del Califato Omeya (siglo IV d la Hégira/X era cristiana), Granada.

Mangin, M. -Dir.- (2004), Le fer, Collections Archéologiques dirigée par Alain Frediére, Editions Errance, Paris.

Marín y Beltrán de Lis, A. (1917), "Estudio petrográfico de las rocas hipogénicas de Marruecos: Ceuta", Boletín del Instituto Geológico de España, 18/2 ${ }^{a}$ Serie, 329-333.

(1956), Memoria explicativa del mapa geológico de la Zona del Protectorado español en Marruecos, Madrid.

Martínez Enamorado, V. (1998), Epigrafía y poder. Inscripciones árabes de la Madrasa al$\hat{Y}$ adìda de Ceuta, Ceuta. 
Morales Belda, F. (1970), La marina de al-Andalus, Barcelona.

Moreno Garrido, Mª J. (1987), "La cerámica de Cuerda Seca peninsular: origen y dispersión”, $I I$ Congreso de Arqueología Medieval Española, III, Madrid, 33-42.

Morin, P., (1957), Quelques observations sur les gîtes d'antimoine de la région de Ceuta, Rapport Service d'Études des Gîtes Mineraux, $\mathrm{n}^{\mathrm{o}} 547$, Rabat.

Navarro Oltra, V.C. (1998), "Sobre el topónimo Awr.ba del distrito de Denia islámica”, Anaquel de Estudios Árabes, X, 85-95.

Percy, J. (1964), Metallurgy. Iron and Steel, London.

Pérez Rivera, J.M. (2005), "Ceuta y el mar en la antigüedad clásica”, Ceuta de la Prehistoria al fin del Mundo Clásico, Instituto de Estudios Ceutíes, Ceuta, 147-170.

Pérez Rivera, J.M. y Bernal Casasola, D. (1995), "Reflexiones sobre la ocupación romana y tardoantigua de Septem. Las intervenciones arqueológicas en el Paseo de las Palmeras (Ceuta)", Cuadernos de Prehistoria y Arqueología de la Universidad Autónoma de Madrid, 22, 181-198.

Pineda, A., Sánchez, M., Salazar, A., Camarero, Y., Navas, M. Delgado, B., y García, J. (2013), Mapa Geológico de España escala 1:50.000. Ceuta, Instituto Geológico y Minero de España, Madrid.

Piñatel, F., Gómez, Mª I., Giles, F. y Finlayson, C. (2001), "Las atarazanas medievales de Gibraltar", Almoraima, 2, 221-238.

Pleiner, R. -Edit.- (1989), Archaeometallurgy of Iron, Praga.

Ramos Espinosa de los Monteros, A. (1998), Ceuta 1.900 (A. Baeza Herrazti, ed.), Ceuta.

Ramos, J.,Castañeda, V. y Bernal, D. (2005), "La secuencia de la Calililla de Benzú (Ceuta) en el contexto regional atlántico-mediterráneo", Ceuta de la Prehistoria al fin del Mundo Clásico, Instituto de Estudios Ceutíes, Ceuta, 21-44.

Roldán Castro, F. (2005), “Textos árabes haciendo referencia a Saltés”, Excavaciones en la Isla de Saltés (Huelva) 1988-2001 (A. Bazzana y J. Bedia, Dirs.), Sevilla, 379-383.

Salkield, L.U. (1970), "Ancient slags in the South West of Iberian Peninsula", Minería Hispana e Iberoamericana. Contribución a su estudio,
León (1970), 85-98.

Sureda Blanes, F. (1925), Abyla Herculana. Introducción al estudio de la etnología berberisca y al de la historia de Ceuta, Calpe.

Terrase, H. (1962), "Monuments de Ceuta d'apres la description d'al-Ansari”, Al-Andalus, XXVII, 442-448.

Torres Balbás, L. (1946), “Atarazanas hispanomusulmanas”, Al-Andalus, XI, 130-172.

Torremocha Silva, A. (2012), "El fenómeno urbano portuario en el Estrecho Medieval”, II Congreso Internacional de la Ciudad en al-Andalus y el Magreb, Granada, 319-325.

Trauth, N. (2005), "El sector 7. Los talleres y los vestigios de una metalurgia medieval”, Excavaciones en la Isla de Saltés (Huelva) 19882001 (A. Bazzana y J. Bedia, Dirs.), Sevilla, 199212.

Tycolete, R.F. (1984), A history of metallurgy, London.

Vallejo Girvés, M. (2005), "El Estrecho de Gibraltar y Ceuta en la literatura bizantina de los siglos VI-VII", Ceuta de la Prehistoria al fin del Mundo Clásico, Instituto de Estudios Ceutíes, Ceuta, 185-202.

(2012), Hispania y Bizancio. Una relación desconocida, Madrid.

Vallvé Bermejo, J. (1962), "Descripción de Ceuta musulmana en el siglo XV", Al-Andalus, XXVII, 398-442.

(1980), "La industria en al-Andalus", Al-Qantara, 1, 209-241.

(1989), Nuevas ideas sobre la conquista árabe de España: toponimia y onomástica, Real Academia de la Historia, Madrid.

Veyne, P.- Dir.- (1987), Historia de la vida privada, I. Del Imperio romano al año mil, Madrid.

Villada Paredes, F. -Coord- (2000), Historia de Ceuta. De los orígenes al año 2000, Instituto de Estudios Ceutíes, Ceuta.

Villada, F. y Gurriarán, P. (2013), "Recientes investigaciones sobre las fortificaciones del Califato Omeya en el Estrecho de Gibraltar (Tarifa, Algeciras, Tánger, Ceuta)", Fortificações e território na Península Ibérica e no Magreb (séculos VI a XVI), Lisboa, 51-62.

Villada, F. Ramón, J. y Suárez, J. (2010), El asentamiento protohistórico de Ceuta. Indigenas y fenicios en la orilla norteafricana del Estrecho de Gibraltar, Ceuta. 
